\title{
Candidate inflammatory biomarkers display unique relationships with alpha-synuclein and correlate with measures of disease severity in subjects with Parkinson's disease
}

Lori N. Eidson', George T. Kannarkat', Christopher J. Barnum', Jianjun Chang', Jaegwon Chung', Chelsea Caspell-Garcia², Peggy Taylor ${ }^{3}$, Brit Mollenhauer ${ }^{4,5}$, Michael G. Schlossmacher ${ }^{6}$, Larry Ereshefsky ${ }^{7}$, Mark Yen ${ }^{8}$, Catherine Kopil ${ }^{9}$, Mark Frasier ${ }^{9}$, Kenneth Marek ${ }^{10}$, Vicki S. Hertzberg ${ }^{11}$ and Malú G. Tansey ${ }^{1 *}$

\begin{abstract}
Background: Efforts to identify fluid biomarkers of Parkinson's disease (PD) have intensified in the last decade. As the role of inflammation in PD pathophysiology becomes increasingly recognized, investigators aim to define inflammatory signatures to help elucidate underlying mechanisms of disease pathogenesis and aid in identification of patients with inflammatory endophenotypes that could benefit from immunomodulatory interventions. However, discordant results in the literature and a lack of information regarding the stability of inflammatory factors over a 24-h period have hampered progress.

Methods: Here, we measured inflammatory proteins in serum and CSF of a small cohort of PD $(n=12)$ and agematched healthy control $(\mathrm{HC})$ subjects $(n=6)$ at 11 time points across $24 \mathrm{~h}$ to (1) identify potential diurnal variation, (2) reveal differences in PD vs HC, and (3) to correlate with CSF levels of amyloid $\beta$ (A $\beta$ ) and a-synuclein in an effort to generate data-driven hypotheses regarding candidate biomarkers of PD.

Results: Despite significant variability in other factors, a repeated measures two-way analysis of variance by time and disease state for each analyte revealed that serum IFNY, TNF, and neutrophil gelatinase-associated lipocalin (NGAL) were stable across $24 \mathrm{~h}$ and different between $\mathrm{HC}$ and PD. Regression analysis revealed that C-reactive protein (CRP) was the only factor with a strong linear relationship between CSF and serum. PD and HC subjects showed significantly different relationships between CSF A $\beta$ proteins and $a$-synuclein and specific inflammatory factors, and CSF IFNy and serum IL-8 positively correlated with clinical measures of PD. Finally, linear discriminant analysis revealed that serum TNF and CSF a-synuclein discriminated between PD and HC with a minimum of 82\% sensitivity and $83 \%$ specificity.

Conclusions: Our findings identify a panel of inflammatory factors in serum and CSF that can be reliably measured, distinguish between PD and $\mathrm{HC}$, and monitor inflammation as disease progresses or in response to interventional therapies. This panel may aid in generating hypotheses and feasible experimental designs towards identifying biomarkers of neurodegenerative disease by focusing on analytes that remain stable regardless of time of sample collection.
\end{abstract}

Keywords: Parkinson's disease, Inflammation, Protein biomarkers, Daily rhythm, CSF, Serum

\footnotetext{
* Correspondence: malu.tansey@emory.edu

${ }^{1}$ Department of Physiology, Emory University, 615 Michael Street, 605L

Whitehead Biomedical Res. Bldg., Atlanta, GA 30322, USA

Full list of author information is available at the end of the article
} 


\section{Background}

A growing body of literature supports a role for peripheral and central immune cells and inflammation in the pathogenesis and progression of neurodegenerative diseases including Parkinson's disease (PD) [1-5]. Yet the major focus in identification of biomarkers for Parkinson's disease (PD) to date has focused solely on neuronal proteins (e.g., $\alpha$-synuclein, tau, and $\beta$-amyloid) because these proteins are known to play a role in the fundamental pathophysiology of neurodegenerative diseases; and in PD patients, the levels of $\alpha$-synuclein have been found to be decreased in the CSF compared to that of $\mathrm{HC}$ individuals [6], a phenotype which does not change significantly within the first months after diagnosis [7] and suggests these proteins are not being efficiently removed from the brain parenchyma. However, inflammatory markers of disease have gained interest as potential, earlier indicators of neurodegenerative disease processes and may have a predictive value. Age is the most common risk factor for development of $\mathrm{PD}$; like other immune cells, microglia display age-dependent changes in activation and regulation [8]. Post mortem analysis of CSF and brain tissue consistently indicates the presence of activated microglia, increased levels of cytokines likely to be microglialderived, increased NFkB activation, and oxidative damage at autopsy [9-12]. Brain imaging of live subjects confirms increased inflammation in the pons, basal ganglia, striatum, frontal cortex, and temporal cortex in PD [13-15], and pre-clinical animal models [16-24], and clinical studies $[9,10]$ demonstrate that inflammation-derived oxidative stress and cytokine-dependent toxicity contribute to nigrostriatal pathway degeneration $[3,25,26]$. These inflammatory factors are considered to derive from chronically activated microglia and invading immune cells responding to aggregation of toxic $\alpha$-synuclein oligomers, early neuronal dysfunction [25], and dying neurons in later disease stages [2], and play a pivotal role in the initiation and propagation of illness.

Although there is no consensus on the role of inflammation as a primary, causative, or early factor in PD or a secondary byproduct of disease, and the role of inflammation in PD is still a hypothesis, there is a great interest in establishing which inflammatory markers can help stage disease and identify disease endophenotypes, to inform immunomodulatory interventions, as has been effectively demonstrated in multiple sclerosis [27], for example. To this end, several studies have sampled biofluids for correlation with disease state. However, these data are conflicting and difficult to interpret. A recent meta-analysis [28] revealed that not all studies indicate elevation of key inflammatory factors but most report significant differences between PD and healthy controls, suggesting that PD is accompanied by a dysregulated inflammatory response. Specifically, several studies reported increased inflammation in CSF [29-32] and serum [33] of PD subjects, but there is disagreement regarding direction of change for several markers. For instance, serum IFN $\gamma$ has been reported to be increased [33], decreased [34], and not different [28] in PD subjects at various stages compared with HCs. Similarly, serum TNF has been reported to be increased in PD subjects compared with age-matched $\mathrm{HC}$ subjects [33-37], but decreased serum TNF levels [38] have also been reported. These disparities may be due to differences in disease severity, other comorbidities, different operating protocols, individual variability, differences in sample processing, analytical methodologies, and almost certainly differences in sampling times coupled with diurnal fluctuations of inflammatory proteins.

Herein, we describe CSF and serum inflammation at 11 time points across a 24-h period (spanning in effect $26 \mathrm{~h}$ ) in PD patients and age-matched $\mathrm{HC}$ subjects in an effort to identify a subset of readily detectable and stable inflammatory factors. The first part of this study evaluated the stability of key CSF biomarkers, alpha-synuclein, DJ-1, and Abeta1-42 in young healthy volunteers in a two period study using the same sampling schedule as outlined here. A minimum of two weeks separated the repeat sampling for blood and CSF [43]. Given that endogenous cortisol levels peak in the morning [39] and can affect cytokine levels [40, 41], we hypothesized that a subset of inflammatory factors in central and/or peripheral compartments display normal diurnal variations in $\mathrm{HC}$ subjects and these may be disrupted in patients with $\mathrm{PD}$. We further hypothesize that a subset of inflammatory markers does not display diurnal variability and may be different between $\mathrm{HC}$ and PD subjects and represent potential disease-specific inflammatory markers. Our goals were to identify the variability in potential candidate biomarkers of inflammation to power larger studies and generate hypotheses, to examine relationships between CSF and serum inflammation for each inflammatory factor, to examine associations between peripheral and central inflammatory factors and CSF levels of $\alpha$-synuclein, $\beta$-amyloid 1-40 (A $\left.\beta_{40}\right)$, and 1-42 $\left(\mathrm{A} \beta_{42}\right)$, and to define an ideal set of inflammatory factors in serum and CSF to be used in conjunction with levels of CSF $\alpha$-synuclein and A $\beta$ proteins to distinguish $\mathrm{PD}$ vs $\mathrm{HC}$ subjects with sensitivity and specificity.

\section{Methods}

\section{Subject inclusion/exclusion criteria}

A total of $18 \mathrm{PD}$ and $8 \mathrm{HC}$ subjects were screened; of these, 12 subjects with PD (as diagnosed by a movement disorder-trained physician based on the widely employed criteria [42]) and 6 age-matched HC subjects were included. All study participants completed the study except one PD subject who dropped out of CSF collection due to minor discomfort. There were no significant differences in age, weight, or body mass index (BMI) between the PD and $\mathrm{HC}$ groups. PD subjects must have 
had at least two of the following symptoms: resting tremor, bradykinesia, or rigidity (either resting tremor or bradykinesia), a diagnosis of PD for $\leq 10$ years, and a Hoehn and Yahr (H\&Y) stage of I-III. HC subjects with current clinically significant neurological disorder and/ or a first-degree relative with idiopathic PD were excluded. Twenty-eight days prior to sample collection and 1 day prior to sample collection, subjects underwent physical and neurological examination, Unified Parkinson's Disease Rating Scale (UPDRS) assessment, $H \& Y$ assessment, spinal $x$-ray (unless taken within the last 12 months), vital signs, medical and medication history, 12-lead electrocardiogram (ECG), safety laboratory assessments, coagulation screening, urine drug screening, urine ethanol screening, Hepatitis B and C screening, HIV testing, and serum pregnancy testing (females). Study participants were not taking prescription or non-prescription drugs within 7 days or 5 half lives (whichever is longer) of sample collection, with the exception of PD subjects taking a stable dose (for 4 or more weeks) of PD medication (amantadine, dopamine agonists, L-DOPA, and/or MAO-B inhibitors) prior to sample collection.

\section{Study design}

Subjects were admitted to the clinic the day prior to sample collection for baseline assessments, as described above. Lumbar and venous catheters were inserted, and CSF and blood were collected concurrently over $26 \mathrm{~h}$ (i.e., at $\sim 5: 30 \mathrm{AM}$, time 0 ; within $30 \mathrm{~min}$ of catheterization, $1,2,4,6,10,12,16,20,24$, and $26 \mathrm{~h}$ post catheterization). Vital signs were taken regularly, and subjects remained in the clinic for at least $24 \mathrm{~h}$ following sample collections for monitoring, and a final neurological examination before discharge. Study procedures were safe and well tolerated with no serious adverse events related to the procedure [43].

\section{Sample collection and handling}

The samples were accessed through the $24 \mathrm{~h}$ Biofluids bank, a subset of a large Michael J. Fox Foundation biospecimen bank available to the community (https:// www.michaeljfox.org/page.html?id=193\&navid=databiospecimens). CSF samples were collected via intrathecal catheter connected to a peristaltic roller pump. Sample collection $(6 \mathrm{ml})$ started approximately $12 \mathrm{~min}$ before each identified sampling time and was concluded approximately $6 \mathrm{~min}$ after. The catheter was cleared of any residual CSF before sample collections to ensure fresh sampling. CSF samples were centrifuged at $\times 1600 \mathrm{~g}$ for $15 \mathrm{~min}$ at $4{ }^{\circ} \mathrm{C}$, supernatants were transferred into six $0.5 \mathrm{~mL}$-aliquots and three $1.0 \mathrm{~mL}$-aliquots in polypropylene tubes, and stored at $-80{ }^{\circ} \mathrm{C}$ or on dry ice within $1 \mathrm{~h}$ of collection. CSF samples contaminated with blood were discarded. The quality of the CSF samples was visually colorless, and red blood cell (RBC) analysis from the 2-ml discard sample was conducted at each time point. The analysis was conducted within $1 \mathrm{~h}$ of sample collection. Whole blood $(10 \mathrm{ml})$ was collected in red top vacutainers, centrifuged at $\times 1350 \mathrm{~g}$ for $15 \mathrm{~min}$ at $4{ }^{\circ} \mathrm{C}$, serum was transferred into six $0.5 \mathrm{~mL}$-aliquots and three $1.0 \mathrm{~mL}$ aliquots, stored in polypropylene cryotubes, and stored at $-80{ }^{\circ} \mathrm{C}$ until shipment on dry ice. All subjects had CSF assessment for blood contamination (hemoglobin ELISA) as part of the safety assessments, typically twice during each catheterization period. In general, if not noted in the clinical study report, this would mean a clinically insignificant finding for RBCs in $~ 98 \%$ of the samples.

\section{ELISA measurements for $\alpha$-synuclein, $A \beta$ proteins, and hemoglobin}

$\alpha$-Synuclein concentration was determined using an ELISA with a luminescent readout (Covance SIG-38974, now BioLegend 8441010 [44]. All samples were run in duplicate at 1:10, 1:20, and 1:50. The reference standards ranged from $6.1-1500 \mathrm{pg} / \mathrm{ml}$. Concentrations of $\alpha$ synuclein were determined by comparing to the reference standard curve using a 4-parameter regression. Recombinant $\alpha$-synuclein from $r$ Peptide was used as the standard. $\mathrm{A} \beta_{1-42}$ was measured using the Betamark Chemilumiescent Assay (Covance, SIG-38952), A $\beta_{1-40}$ was detected using the Covance Sandwich ELISA (Covance, SIG38950), total protein was determined using a BCA protein assay (ThermoFisher/Pierce Bio), and hemoglobin was measured by sandwich ELISA (Bethyl Laboratories) according to manufacturer's instructions.

\section{Multiplexed immunoassay measurements of inflammatory proteins}

Inflammatory proteins were measured using the Meso Scale Discovery (MSD) electrochemiluminescent (ECL) immunoassay V-PLEX human pro-inflammatory panel (i.e., IL-1 $\beta$; detection range: $0.04-1000$ pg/ml, IL-2; 0.09$1000 \mathrm{pg} / \mathrm{ml}, \mathrm{IL}-6 ; 0.06-1000 \mathrm{pg} / \mathrm{ml}, \mathrm{IL}-8 ; 0.04-1000 \mathrm{pg} / \mathrm{ml}$, IL-4; $0.02-100$ pg/ml, IL-10; 0.03-1000 pg/ml, IL-12p70; $0.1-1000 \mathrm{pg} / \mathrm{ml}, \quad \mathrm{IL}-13 ; 0.2-1000 \mathrm{pg} / \mathrm{ml}$, IFN $; 0.2-$ $1000 \mathrm{pg} / \mathrm{ml}$, and TNF; $0.04-100 \mathrm{pg} / \mathrm{ml}$ ) and a V-PLEX human NGAL $(1-10,000 \mathrm{pg} / \mathrm{ml})$ and CRP $(100-100,000 \mathrm{pg} /$ $\mathrm{ml}$ ) panel on the MSD SECTOR Imager 2400-A (Meso Scale Diagnostics, LLC, Rockville, MD) according to manufacturer's instructions. CSF and serum samples were run in duplicate, and serum samples were diluted by a factor of 1. Data were analyzed by laboratory personnel blinded to condition using MSD integrated data analysis software that converts ECL signal to $\mathrm{pg} / \mathrm{mL}$ values based on standard 
curves of calibrator proteins. All \% coefficient of variation $(\mathrm{CV})$ values for samples analyzed were below $5 \%$.

\section{Statistical analysis and data presentation}

As an ad hoc means of determining stability over time, we performed linear regression of each analyte over time for each individual. Inflammatory factors with no significant association with time were classified as "stable," and factors with a significant association with time were classified as "positive" or "negative" according to the sign of the slope estimate (Additional file 1). A Mann-Whitney $U$ rank-sum nonparametric test was used to compare levels of each analyte between $\mathrm{HC}$ and PD subjects at time 0 (Fig. 2 and Additional file 2). We used orthogonal polynomials to examine diurnal patterns, in particular the quadratic effect (Table 1). We applied repeated measures ANOVA to assess the effects of time and to examine differences between HD and PD participants (Fig. 2 and Additional file 3). We also investigated the extent to which levels of an inflammatory marker in serum correlated with its levels in the CSF (Additional file 4). We did not adjust for multiple comparisons given the low group sizes and the nature of this study being exploratory in order to be able to power a larger study. We used repeated measures ANOVA to examine the relationship between serum and CSF inflammatory factor levels across time for each

Table 1 CSF TNF, CRP, IL-8, IL-6, a-synuclein, and A $\beta$ levels were disrupted in PD versus $\mathrm{HC}$

\begin{tabular}{lllll}
\hline Quadratic effect & HC & \multicolumn{3}{l}{ PD } \\
\hline Serum analyte & $F$ statistics & $p$ value & $F$ statistics & $p$ value \\
TNF & $F_{(1,5)}=0.06$ & 0.82 & $F_{(1,11)}=0.02$ & 0.89 \\
IFNY & $F_{(1,5)}=0.48$ & 0.52 & $F_{(1,11)}=1.16$ & 0.31 \\
NGAL & $F_{(1,5)}=2.24$ & 0.19 & $F_{(1,11)}=1.37$ & 0.27 \\
CRP & $F_{(1,5)}=0.09$ & 0.78 & $F_{(1,11)}=3.62$ & 0.08 \\
IL-6 & $F_{(1,5)}=5.37$ & 0.07 & $F_{(1,11)}=0.10$ & 0.76 \\
IL-8 & $F_{(1,5)}=0.11$ & 0.76 & $F_{(1,11)}=2.88$ & 0.12 \\
CSF Analyte & $F_{\text {statistics }}$ & $p$ value & $F_{\text {statistics }}$ & $p$ value \\
TNF & $F_{(1,5)}=5.39$ & 0.07 & $F_{(1,10)}=7.47$ & 0.02 \\
IFNy & $F_{(1,5)}=0.00$ & 0.99 & $F_{(1,10)}=1.24$ & 0.29 \\
NGAL & $F_{(1,5)}=0.16$ & 0.71 & $F_{(1,10)}=0.90$ & 0.37 \\
CRP & $F_{(1,5)}=1.67$ & 0.25 & $F_{(1,10)}=6.51$ & 0.03 \\
IL-6 & $F_{(1,5)}=15.00$ & 0.01 & $F_{(1,10)}=2.97$ & 0.12 \\
IL-8 & $F_{(1,5)}=1.28$ & 0.31 & $F_{(1,10)}=8.45$ & 0.02 \\
a-synuclein & $F_{(1,5)}=3.89$ & 0.11 & $F_{(1,11)}=6.02$ & 0.03 \\
A $\beta_{40}$ & $F_{(1,5)}=26.36$ & 0.004 & $F_{(1,11)}=8.19$ & 0.02 \\
A $\beta_{42}$ & $F_{(1,5)}=5.60$ & 0.06 & $F_{(1,11)}=11.60$ & 0.006 \\
\hline An anays of & and quadric & &
\end{tabular}

An analysis of linear and quadratic trends indicated that levels of CSF inflammation rise and fall across the day in PD subjects more than HC. TNF, CRP, IL-8, $a$-synuclein, and $A \beta_{42}$ levels in the CSF were best fit with a parabolic (not straight) line in PD, but not HC subjects. CSF IL-6 levels were best fit with a parabolic line in $\mathrm{HC}$, but not $\mathrm{PD}$ subject, as well as those between serum and CSF inflammatory markers with CSF $\alpha$-synuclein and $A \beta$ proteins across time (Additional file 5). We used ANCOVA to determine these relationships at baseline (Additional file 6, Fig. 3, and Additional file 7) as well as relationships with UPDRS and its components (Fig. 4, Additional file 8). Data are reported as the mean protein concentration (pg/ $\mathrm{mL}) \pm$ SEM. Finally, we used linear discriminant analysis (LDA) to determine the ability of biomarker groups to discriminate between $\mathrm{HC}$ and PD participants (Fig. 4 and Additional file 9). $p \leq 0.05$ was considered significant.

\section{Results}

While multiple groups have reported alterations in inflammatory markers in the blood and CSF of individuals suffering from neurodegenerative diseases like PD [1], results are discordant [28]. To investigate the extent to which variability between individuals, sampling times, or diurnal patterns in specific inflammatory proteins in the blood or CSF contribute to the lack of consensus, and to generate hypotheses, we pursued a set of specific questions that required a complex set of comparisons of intra-individual and inter-group values (Fig. 1) to investigate the extent of association between inflammatory markers and other parameters of interest.

We measured a subset of inflammatory factors (i.e., IL$1 \beta$, IL-2, IL-6, IL-8, IL-4, IL-10, IL-12, IL-13, IFN $\gamma$, TNF, NGAL, and CRP) in the serum and CSF of PD and agematched HC subjects. IL-1 $\beta$, IL-2, IL-4, IL-10, IL-12, and IL-13 were not reliably above the lower limit of detection for the MSD assay and therefore were excluded from analyses. We also examined the relationship between the consistently detectable inflammatory factors and CSF levels of more established neurodegenerative disease-specific biomarkers, specifically $\alpha$-synuclein, $A \beta_{40}$, and $A \beta_{42}$. Finally, we examined the relationship between serum and CSF factors and PD severity and duration.

\section{Serum IFN $\gamma$, IL-8, NGAL, and TNF and CSF IL-8, NGAL, and TNF levels were relatively stable across the day in most $\mathrm{PD}$ and $\mathrm{HC}$ individuals}

Clinical heterogeneity and inter-individual variability are significant challenges to interpreting clinical data and critical determinants of statistical power. Thus, we first determined individual variability in inflammatory factors across $24 \mathrm{~h}$. Regression analyses revealed marked variability across time in multiple inflammatory factors in both HC and PD subjects (Additional file 1). The most stable analytes across time in the majority of $\mathrm{HC}$ and $\mathrm{PD}$ subjects were serum IFNy, IL-8, NGAL, and TNF and CSF IL-8, NGAL, and TNF. These inflammatory factors were stable in greater than two-thirds of subjects (Additional file 1). Serum and CSF NGAL were stable in $50 \%$ or more of both PD and HC subjects, indicating relative stability. While CSF CRP varied across time in 


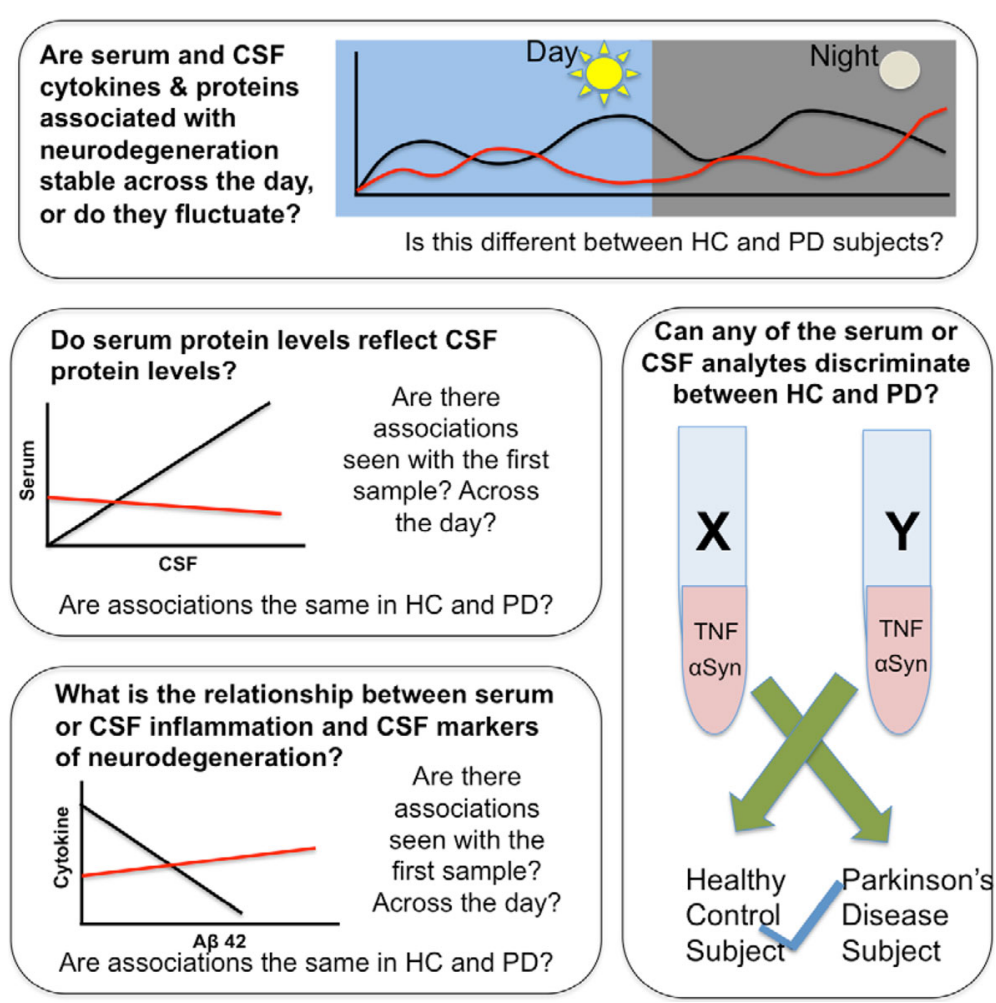

Fig. 1 Key questions: inflammatory markers and neurodegeneratation biomarkers in PD and HC subjects across time. Our analysis addressed the following a priori specified questions aimed at establishing candidate inflammatory biomarkers to focus a larger cross-sectional or longitudinal study: Investigate the extent to which each analyte varied over time in serum and CSF, the extent of correlation between serum and CSF inflammatory factors, the extent of correlation between levels of known markers of neurodegeneration and serum and CSF inflammatory factors, and identification of analytes capable of discriminating between HC and PD subjects with high sensitivity and specificity

slightly half of PD subjects (i.e., CRP levels increased over time in $58.3 \%$ of PD subjects), CSF CRP showed minimal variability in the majority of individuals in the $\mathrm{HC}$ population (i.e., CRP levels increased over time in only $33.3 \%$ of HC subjects). Serum IL-6, CSF IFN $\gamma$, and CSF IL-6 displayed an increase over the 24-h period in greater than two-thirds of $\mathrm{HC}$ subjects, whereas in $\mathrm{PD}$ subjects these analytes were mostly stable across time.

\section{Serum TNF, NGAL, and IFN $\gamma$ are different at baseline in} $P D$ versus $\mathrm{HC}$ and remain relatively stable across the day Despite finding significant within group variability and a relatively small sample size, we found significant differences between serum TNF and serum NGAL levels in PD versus $\mathrm{HC}$ at baseline (time 0; Fig. 2). PD subjects had lower levels of serum TNF (Fig. 2g); $U_{(83,88)}=10 ; p=0.01$ ) and higher levels of serum NGAL $\left(h ; U_{(31,140)}=10 ; p=0.01\right)$ at baseline than age-matched $\mathrm{HC}$ subjects (see Additional file 2). A repeated measures two-way analysis of variance (ANOVA) by time and disease state for each analyte (Fig. 2 and Additional file 3) revealed that certain serum and CSF analytes changed over time but not in a disease-specific manner (CSF TNF; Fig. 2a and serum IL-6; Fig. 2b, left side of Fig. 2 diagram), while others were different between PD and HCs but not stable across time (CSF IL-8; Fig. 2c, CSF $\alpha$ synuclein; Fig. 2d, CSF A 440 ; Fig. 2e, and CSF A $\beta 42$; Fig. 2f, middle in Fig. 2 diagram). However, serum TNF (Fig. 2g), serum NGAL (Fig. 2h), and serum IFNY (Fig. 2i) were stable over the 24-h period and were different between PD and HC groups. Serum TNF (Fig. 2g) and serum IFN $\gamma$ (Fig. 2i) were lower in PD subjects compared to HC subjects $\left(F_{(1,16)}=208.58\right.$; $p<0.0001$, and $F_{(1,16)}=8.49 ; p=0.009$, respectively), and serum NGAL (Fig. $2 \mathrm{~h}$ ) was higher in PD compared to HCs $\left(F_{(1,16)}=25.98 ; p<0.0001\right)$. All three analytes showed minimal variability across time $\left(F_{(10,160)}=0.11 ; p=1.00\right.$, $F_{(10,160)}=0.38 ; \quad p=0.95$, and $F_{(10,160)}=0.73 ; \quad p=0.69$, respectively). CSF $\alpha$-synuclein, $\mathrm{A} \beta_{40}$, and $\mathrm{A} \beta_{42}$ were significantly lower in PD patients as compared with $\mathrm{HC}$ subjects $\left(F_{(1,6)}=8.35 ; p=0.01, F_{(1,6)}=14.69 ; p=0.001\right.$, and $F_{(1,6)}=4.61 ; p=0.05$, respectively). Depending on time of day, these CSF markers were different in PD versus HC subject groups. There were no differences between PD and $\mathrm{HC}$ across time in any other analytes. 

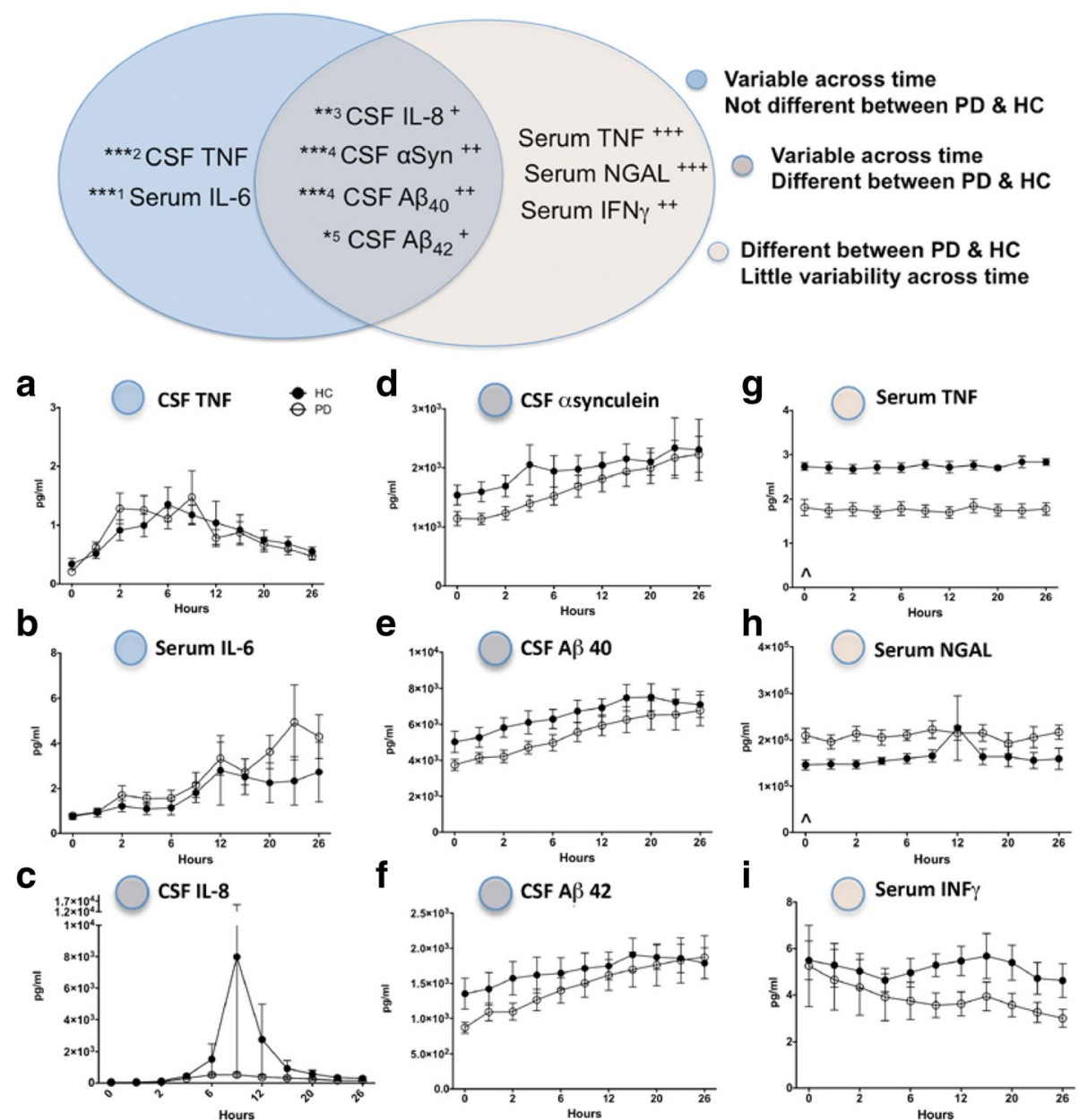

Fig. 2 Serum and CSF profiles differ between PD and HC subjects and show distinct diurnal fluctuations. The top diagram summarizes significant results. When sampled across a 26-h period, protein levels of CSF TNF (a), and serum IL-6 (b) fluctuate significantly across the day $\left(F_{(10,154)}=4.66 ; p<0.00001\right.$, and $F_{(10,160)}=3.12 ; p<0.00001$, respectively). CSF IL-8 (c), a-synuclein $(\mathbf{d}), A \beta_{40}(\mathbf{e})$, and $A \beta_{42}(\mathbf{f})$ are decreased in PD as compared to age-matched $H C$ $\left(F_{(1,16)}=5.08 ; p=0.04, F_{(1,16)}=8.35 p=0.01, F_{(1,16)}=14.69 ; p=0.001\right.$, and $F_{(1,16)}=4.61 ; p=0.05$, respectively), and vary across the day $\left(F_{(10,154)}=2.23\right.$; $p=0.01, F_{(10,160)}=3.30 ; p<0.001, F_{(10,160)}=4.11 ; p<0.0001$, and $F_{(10,160)}=2.15 ; p=0.02$, respectively). Serum TNF $(\mathbf{g})$ and serum IFNy (i) are decreased in PD subjects compared to HC subjects $\left(F_{(1,16)}=208.58 ; p<0.00001\right.$ and $F_{(1,16)}=8.49 ; p=0.009$, respectively), and serum NGAL (h) is increased in PD compared to $\mathrm{HC}$ subjects $\left(F_{(1,16)}=25.98 ; p<0.00001\right)$. When measured at baseline (time $\left.0=5: 30 \mathrm{AM}\right)$, serum TNF $(\mathbf{g})$ was significantly lower in PD subjects as compared with $\mathrm{HC}$ subjects $\left(U_{(83,88)}=10 ; p=0.014\right)$, and serum NGAL $(\mathbf{h})$ was significantly higher in PD subjects as compared with $\mathrm{HC}$ subjects $\left(U_{(31}\right.$, $\left.{ }_{140)}=10 ; p=0.014\right)$. There were no differences between PD and HC in any other analyte (see Table 2 for all data). *Indicates significant change in time, and + indicates significant difference between PD and HC. ${ }^{* *}$ and ${ }^{+++}$indicate $p<0.0001,{ }^{* *}$ and ${ }^{++}$indicate $p<0.01,{ }^{*}$ and ${ }^{+}$indicate $p \leq 0.05$, and $\wedge$ indicates a significant difference between PD and $\mathrm{HC}$ at time $0 ; p<0.05$. Superscript numbers indicate the sampling hour where significant changes occur

\section{Inflammatory proteins in CSF display greater fluctuation in $P D$ versus $H C$ across the day}

We next determined whether inflammatory analytes, $\alpha$-synuclein, and/or $A \beta_{40}$ and $A \beta_{42}$ levels fluctuate across the day by examining quadratic trends for each analyte across time (Table 1). The pattern of CSF $\operatorname{TNF}(p=0.02), \operatorname{CRP}(p=0.03), \quad$ IL-8 $(p=0.02)$, and $\mathrm{A} \beta_{42} \quad(p=0.006)$ levels across the day were best fit by a parabolic (not linear) relationship in PD subjects, but not in HCs $(p=0.07, p=0.25, p=0.31, p=0.06$, respectively), indicating that the levels of these CNS proteins rise and fall across the day more in PD subjects versus
HC. CSF IL-6 levels rise and fall across in the day in HC subjects $(p=0.01)$, but not in PD $(p=0.12)$, and CSF A $\beta_{40}$ levels across the day were best fit by a quadratic trend in both PD $(p=0.02)$ and HC ( $p=0.004)$ subjects.

\section{PD and HC subjects displayed different relationships} between serum and CSF inflammation across the day Next, we investigated the extent to which levels of an inflammatory marker in serum correlated with its levels in the CSF (Additional file 4). Serum CRP and CSF CRP significantly co-varied across time in one group but not the other. Serum IL-6 and CSF IL-6 were significantly 
related in both groups, and the relationships were different in PD and HC subjects. Serum NGAL and CSF NGAL displayed a significant association that was not different between PD and HC subjects. Serum IFN $\gamma$, serum IL-8, and serum TNF did not covary with CSF analytes but were different between the two groups across time (see Additional file 4 for statistics). These data indicate that CSF and serum levels of IL-6 and CRP display significant correlations across a 24-h period and that they do so in a unique way in HC and PD subjects.

\section{CSF and serum CRP positively covary in PD and HC subjects at baseline}

Next, we examined the relationship between serum and CSF inflammatory factors using the samples from the first collection period (time 0 ). We found no significant correlation between serum and CSF levels of any factor except CRP (Additional file 6a). Serum and CSF CRP significantly correlated in $\mathrm{HC}$ (slope $=325 \pm 86.9, F_{(1,4)}$ $=14.0 ; p=0.02)$ and in PD (slope $=415.5 \pm 26.6, F_{(1,10)}$ $=243.8 ; p<0.0001)$, but the slopes did not differ between $\mathrm{HC}$ and PD subjects $(t(16)=1.28 ; p=0.22)$ (a). Serum and CSF NGAL (b), TNF (c), IL-6 (d), IL-8 (e), and IFNY (f) did not correlate at baseline, indicating that serum and CSF levels of these factors do not reflect one another (Additional file 6).

\section{PD and HC subjects displayed different relationships} between biofluid inflammation and CSF a-synuclein, $A \beta_{40}$, and $A \beta_{42}$ proteins across the day and at baseline

Next, we investigated the relationship between levels of inflammatory markers and $\alpha$-synuclein, $A \beta_{40}$, and $A \beta_{42}$, which are frequently assayed as potential biomarkers of neurodegenerative disease (Additional file 5). Interestingly, with respect to CSF $\alpha$-synuclein, $\mathrm{HC}$ and PD subjects displayed different relationships between this biomarker and serum IFN $\gamma$, serum NGAL, serum CRP, CSF TNF, and CSF CRP. With respect to CSF A $\beta_{40}$, HC and PD subjects displayed different relationships between this biomarker and serum IFN $\gamma$, serum NGAL, serum CRP, serum IL-8, CSF TNF, CSF NGAL, CSF CRP, and CSF IL-8. Finally, with respect to $A \beta_{42}, H C$ and $\mathrm{PD}$ subjects displayed different relationships between this biomarker and serum IFN $\gamma$, serum CRP, CSF TNF, CSF NGAL, CSF CRP, CSF IL-6, and CSF IL-8. (see Additional file 5 for statistics).

Next, we examined the relationship between CSF $\alpha$ synuclein, $A \beta 40$, and $A \beta 42$ levels with serum and CSF inflammatory factors analyzed at baseline (time 0 ). At time 0, CSF NGAL, CSF IFN $\gamma$, CSF CRP, and serum CRP co-varied with $\alpha$-synuclein, $A \beta_{40}$, and $A \beta_{42}$ in a disease-dependent manner (Fig. 3): PD subjects demonstrated a relationship between CSF NGAL and CSF $\alpha$ synuclein (Fig. 3a) as well as CSF NGAL and CSF A $\beta_{40}$ (b), while $\mathrm{HC}$ subjects did not. $\mathrm{HC}$ subjects demonstrated a relationship between CSF IFN $\gamma$ and CSF $\alpha-$ synuclein (c), CSF CRP and CSF $A \beta_{40}$ (d), and serum CRP and CSF $A \beta_{40}$ (e), while PD subjects did not (Fig. 3; Additional file 7 for statistics).

\section{CSF IFN $\gamma$ and serum IL-8 positively correlate with some clinical measures in PD subjects, and serum TNF and CSF a-synuclein correctly categorize individuals into PD or HC groups with high specificity and sensitivity}

Next, we analyzed relationships between serum and CSF inflammation and clinical measures of disease state as determined by the UPDRS, its components (mentation, behavior, and mood score, activities of daily living score, motor examination score, and complication of therapy score), and disease duration (years since PD diagnosis; Fig. 4 and Additional file 8 for statistics). Interestingly, levels of CSF IFNY increased as the UPDRS increased (Fig. 4a). When UPDRS component scores were examined separately, CSF IFN $\gamma$ levels increased as the activities of daily living (ADL) score (Fig. 4b) and the complication of therapy score (Fig. 4c) increased, indicating that the highest levels of CSF IFN $\gamma$ are found in PD subjects with the most disruption of daily living activities and the most complication experienced due to therapeutic treatment. Serum IL-8 levels demonstrated a significant positive relationship with the ADL score (Fig. 4d), such that subjects with the highest levels of serum IL-8 have the most disruption in their daily activities due to PD. There were no other significant correlations noted between PD severity or disease duration and inflammation in the serum or CSF. There were no relationships noted between serum or CSF inflammatory markers and years with PD or disease severity or duration and CSF neurodegenerative markers (i.e., $\alpha$ synuclein, $A \beta_{40}$, and $A \beta_{42}$; data not shown).

Given that inflammatory status results from a convergence of multiple variables and factors, we used linear discriminant analysis (LDA) to determine if any particular analyte or a particular set of analytes allowed for correct assignment of group membership (with all sampling time points considered). LDA revealed that inflammation and a neurodegenerative disease marker correctly assign individuals to $\mathrm{HC}$ or PD groups. Indeed, serum TNF alone misclassified only $17 \%$ of PD subjects into the $\mathrm{HC}$ group and only $17 \%$ of $\mathrm{HC}$ subjects (Fig. 4e). Serum TNF with CSF $\alpha$-synuclein together correctly categorized $>75 \%$ of both PD and HC groups across all time points (Fig. 4f; $82 \%$ sensitivity and $83 \%$ specificity) which was the most accurate of all parameter combinations tested.

Serum and CSF IL-6 alone incorrectly assign 100\% of $\mathrm{HC}$ individuals into the PD group (Additional file 9). While serum and CSF levels of IL-6 correctly categorized 

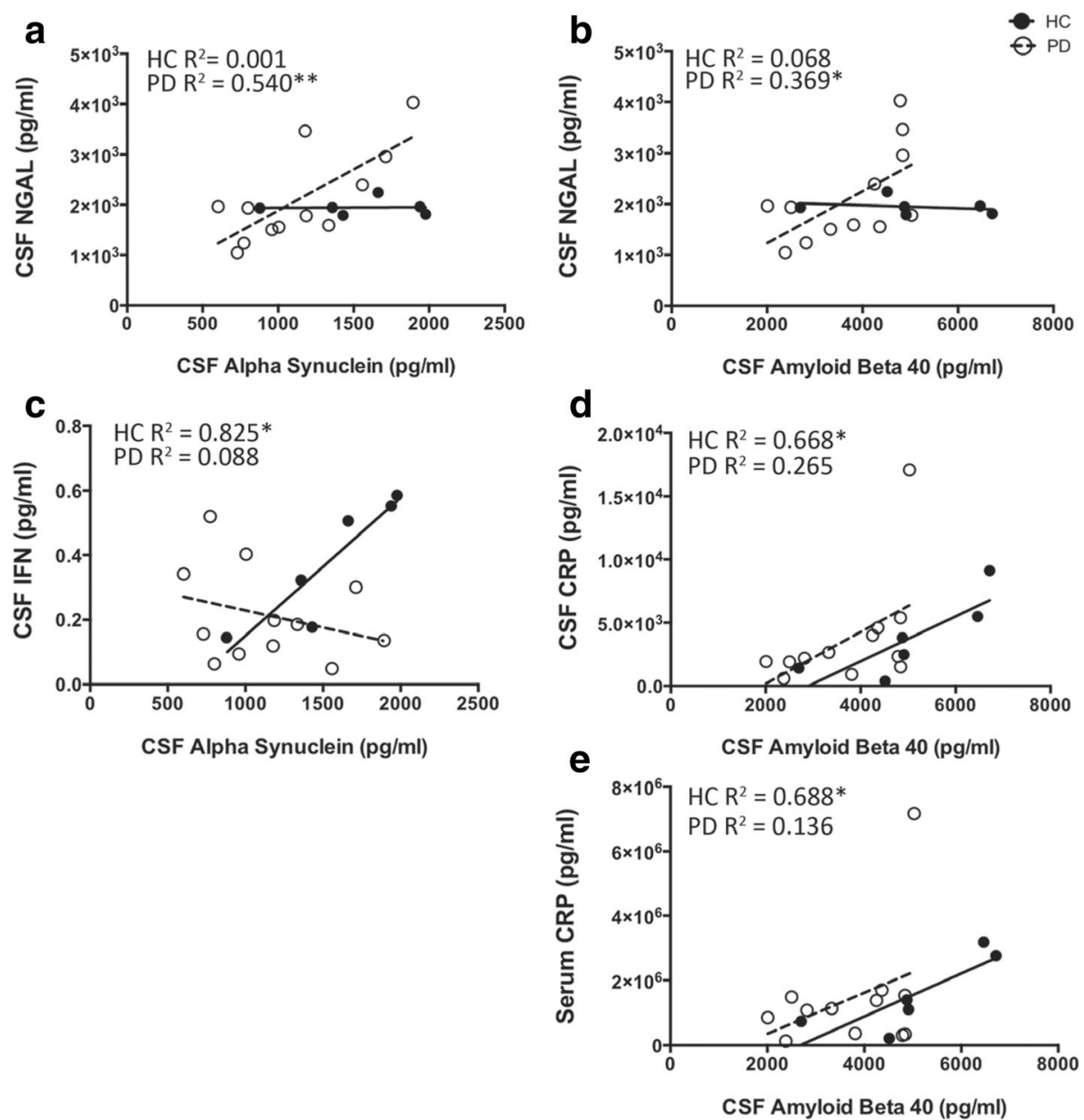

Fig. 3 At time 0, CSF NGAL, IFNy, CRP, and serum CRP disease-dependently covary with ABs. PD subjects demonstrate a relationship between CSF NGAL and CSF a-synuclein $(\mathbf{a} ; F(1,10)=11.73 ; p=0.007)$ as well as CSF NGAL and CSF A $440(\mathbf{b} ; F(1,10)=5.86 ; p=0.04)$, while HC subjects do not. HC subjects demonstrate a relationship between CSF IFNy and CSF a-synuclein ( $\mathbf{c} ; F(1,4)=18.88 ; p=0.01)$, CSF CRP and AB40 (d; $F(1,4)=8.03 ; p=0.05)$, and serum CRP and $A \beta 40(\mathbf{e} ; F(1,4)=8.80 ; p=0.04)$, while PD subjects do not (see Additional file 7 for all correlation data). * indicates $p<0.05$ and ${ }^{* *}$ indicates $p<0.01$

at least $75 \%$ of individuals into the PD group across time (Additional file 9a), these two factors were not sufficient to discriminate between $\mathrm{HC}$ and age-matched PD subjects. Similar results were obtained when only serum IL-6 was considered (Additional file $9 \mathrm{~b}$ for all data).

\section{Discussion}

Several studies have investigated the extent to which Parkinson's disease (PD) pathophysiology is associated with increased inflammatory status. However, due to conflicting results [28], there is no agreement on which inflammatory proteins hold promise as potential biomarkers to stage or monitor disease progression, and a clear picture of biofluid inflammation in PD is stymied by a complete lack of knowledge of the extent of diurnal fluctuations in inflammatory proteins in peripheral (serum, plasma) and central (CSF) compartments in both healthy control $(\mathrm{HC})$ subjects and PD patients.
Here, we analyzed the levels of six inflammatory proteins (i.e., IL-6, IL-8, IFN $\gamma$, TNF, NGAL, and CRP) concurrently across a 26-h sampling period in the serum and CSF of PD $(n=12)$ and age-matched HC subjects $(n=$ 6). The key findings are summarized in Table 2 .

We stress that the sample size of this study is very small and designed to generate new hypotheses and inform a larger study. While age and BMI were controlled for (Additional file 10), and inclusion/exclusion criteria were strictly adhered to for recruitment of subjects (Additional file 11), some factors that may influence cytokine profiles were not considered. For example, PD subjects taking a stable dose of PD medication (amantadine, dopamine agonists, L-DOPA, and/or MAO-B inhibitors) for 4 weeks prior were included, and drug dose and drug type were not controlled. Dopaminergic drugs increase inflammation in PD and PD models [45-48], and increased inflammation after long-term L-DOPA 

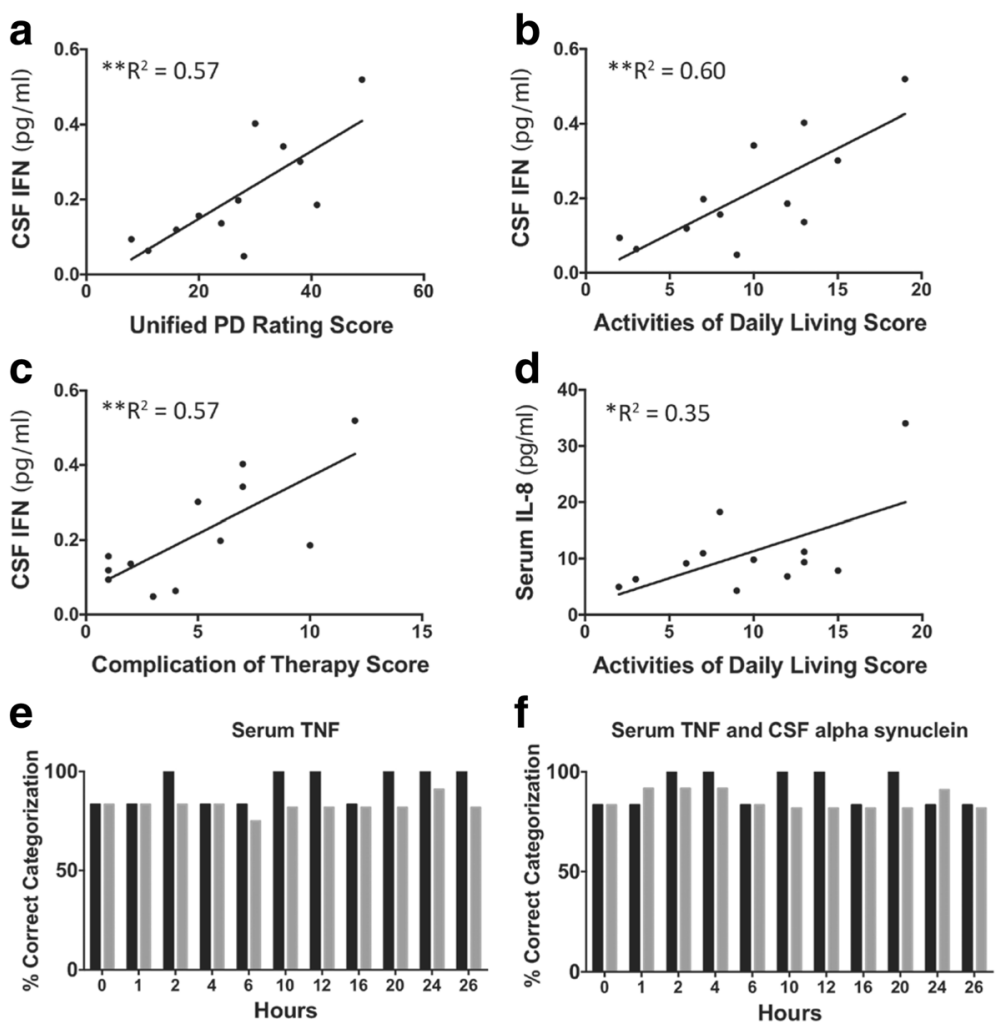

Fig. 4 Inflammation correlates with UPDRS and predicts disease phenotype with sensitivity and specificity across the day. When measured at baseline (time $0=5: 30 \mathrm{AM})$, CSF IFNy positively correlates with the UPDRS $(\mathbf{a} ; p=0.004)$, as well as the Activities of Daily Living Score component of the UPDRS $(\mathbf{b} ; p=0.003)$ and the Complication of Therapy Score $(\mathbf{c} ; p=0.005)$. Serum IL-8 positively correlated with the Activities of Daily Living Score $(\mathbf{d} ; p=0.04)$. There were no other significant correlations between inflammation and disease severity or number of years with disease. Serum TNF alone (e) and serum TNF with CSF a-synuclein (f) demonstrated ascending accuracy and precision in discriminating between HC and PD subjects when analyzed with linear discriminant analyses (LDA; see Additional file 9: Figure S2 for all LDA factors considered)

Table 2 Summary of findings. Serum IFNy, serum NGAL, serum TNF, and serum CRP, CSF NGAL, CSF TNF, CSF IFNy, and CSF CRP display several characteristics of candidate biomarkers

\begin{tabular}{|c|c|}
\hline Biomarker characteristic & Analyte \\
\hline Diurnal stability in most PD and $\mathrm{HC}$ individuals (Additional file 1; top) & $\begin{array}{l}\text { Serum IFNY, IL-8, and TNF } \\
\text { CSF IL-8 and TNF }\end{array}$ \\
\hline $\begin{array}{l}\text { Diurnal stability and different between PD and HC (Additional file 1; } \\
\text { bottom, Fig. 2, Additional file 2, Additional file 3, and Table 1) }\end{array}$ & Serum IFNY, NGAL, and TNF \\
\hline $\begin{array}{l}\text { Different relationship between CSF and serum levels across the day } \\
\text { in PD and HC (Additional file 4) }\end{array}$ & Serum and CSF CRP and IL-6 \\
\hline $\begin{array}{l}\text { CSF and serum levels covary at time } 0 \text { in both PD and HC subjects } \\
\text { (Additional file 6) }\end{array}$ & CRP \\
\hline $\begin{array}{l}\text { Covary with a syn and } A \beta \text { peptides across the day, and PD and } \mathrm{HC} \\
\text { subjects have different diurnal relationships (Additional file } 5 \text { ) }\end{array}$ & $\begin{array}{l}\text { Serum IFNY and CRP } \\
\text { CSF TNF and CRP }\end{array}$ \\
\hline $\begin{array}{l}\text { Different relationship with a syn and } A \beta \text { peptides between PD and } \\
\mathrm{HC} \text { at time } 0 \text { (Fig. } 3 \text { and Additional file } 7 \text { ) }\end{array}$ & $\begin{array}{l}\text { Serum CRP } \\
\text { CSF IFNY, NGAL, and CRP }\end{array}$ \\
\hline Covary with UPDRS or components (Fig. 4 and Additional file 8) & $\begin{array}{l}\text { Serum IL-8 } \\
\text { CSF IFNY }\end{array}$ \\
\hline $\begin{array}{l}\text { Correctly categorizes } \geq 75 \% \text { of individuals into appropriate group } \\
\text { (PD or HC; Additional file 9) }\end{array}$ & $\begin{array}{l}\text { Serum TNF alone }(75 \%+) \\
\text { Serum TNF with CSF a syn }(80 \%+)\end{array}$ \\
\hline
\end{tabular}


treatment may contribute to the development of dyskinesia $[46,47]$. However, there is some evidence that DA drugs decrease inflammation [49] or do not change circulating inflammation at all [50]. Our concerns about the potential confounding effects of dopaminergic therapy are lessened given that dopaminergic drugs did not skew inflammatory levels up or down across the board. Despite the fact that not all patients were on the same kinds of medication, which is usually the case in the clinic, we were able to find PD-specific attributes to some of the analytes. These and other factors could influence inflammation [51,52], and should be taken into account in future studies.

While we found significant temporal variability in both $\mathrm{PD}$ and $\mathrm{HC}$ groups across the day in many serum and CSF inflammatory factors, serum IFN $\gamma$ displayed stability across the day in $83 \%$ of $\mathrm{HC}$ individuals and $92 \%$ of PD individuals, and both serum and CSF TNF displayed stability across the day in $100 \%$ of HCs and $92 \%$ of PD subjects. These data suggest NGAL and particularly TNF in the serum may be good candidate biomarkers to pursue as indicators of inflammatory state in crosssectional studies where it may not be possible to adhere to an exact sampling time. Differences were noted between PD and HC groups in serum TNF and NGAL at time 0 with TNF being significantly decreased, and NGAL being significantly increased in PD. While serum IFN $\gamma$ levels are more variable within groups than serum TNF or NGAL, significant differences in serum IFN $\gamma$ were noted between $\mathrm{HC}$ and PD groups when all time points are considered, with IFNy being significantly lower in PD subjects as compared with $\mathrm{HC}$ subjects. However, differences in serum IFN $\gamma$ between PD and $\mathrm{HC}$ subjects were not noted at baseline (time 0 ), indicating that multiple sampling points may be required. However, repeated sampling protocols increase intra-subject variability of CSF A $\beta$ protein levels [53], highlighting the importance of choosing a relatively stable biomarker.

Identification of TNF and IFNY as potential candidate biomarkers is noteworthy given that both of these cytokines have been strongly implicated in degeneration of nigral dopaminergic neurons and basal ganglia pathologies in pre-clinical and post mortem studies [54-63]. Levels of serum TNF have been reported to be increased in PD subjects compared with age-matched $\mathrm{HC}$ subjects [33-35, 37], but decreased serum TNF levels [38] as well as no difference in serum TNF levels [64] have been reported in PD versus $\mathrm{HC}$ subjects. As our data indicate stability in the levels of serum TNF across the day both individually, and within groups, we likely rule out that diurnal variability accounts for this disparity in the TNF literature. In a recent meta-analysis of inflammatory serum levels in PD subjects and HCs, Qin and colleagues [28] determined that of the 25 studies considered in the analysis, 9 demonstrated an increase of serum TNF levels in PD. However, age was found to be a confounding factor. Like serum TNF, serum IFN $\gamma$ has also been demonstrated to be increased [33] and decreased [34] in PD subjects compared with HCs. Here, we demonstrate that when all sampling time points are considered, there is a discernable decrease in serum IFN $\gamma$ in PD subjects compared with HCs. These data suggest that sampling time (and/or other circumstances of collection) could account for IFN $\gamma$ variability reported in the literature, as we found no difference between $\mathrm{HC}$ and PD subjects in serum IFN $\gamma$ at time 0 , and a moderate, though insignificant, degree of variability across the 24-h period in both HC and PD groups. Standardizing sampling paradigms (e.g., number of samples, volume of each sample, total sample volume) and differences between CSF collection methods (e.g., gravity drip, syringe draw, peristaltic pump in a closed system as used here) would likely reconcile some inconsistencies in the literature [53].

Together, our results strongly suggest that serum TNF and serum NGAL are the most promising candidate inflammatory biomarkers because they remain relatively invariant throughout a 24 -h period in the majority of subjects and because their levels are significantly different between PD and $\mathrm{HC}$ groups both at time 0 and across the day. To our knowledge, this is the first study to investigate NGAL protein levels in blood or CSF of PD subjects. NGAL (also known as lipocalin 2, 24p3, uterocalin, and siderocalin) is an acute phase protein [65] involved in innate host defense against bacteria [66] that is both upstream and downstream of TNF signaling, and sensitizes cortical neurons to $\beta$-amyloid toxicity [67]. Several studies have identified increases in NGAL in subjects with familial amyloid polyneuropathy [68] and more recently in patients with late-life depression [69-71], Down's syndrome with dementia [72], and Alzheimer's disease with depression [73]. Finally, CSF NGAL holds great potential as a novel companion inflammatory biomarker in PD because it is easy to measure, it is stable across time, and it is part of a signaling network with TNF [67].

We next demonstrated that CSF TNF, CRP, IL-8, and $\mathrm{A} \beta_{42}$ levels fit a quadratic equation indicating a parabola shape when graphed across the day (i.e., significantly changed from time 0 levels and then significantly changed back toward time 0 levels) in PD subjects but not HCs. CSF IL-6 levels rise and fall across in the day in $\mathrm{HC}$ subjects, but not PD, and CSF A $\beta_{40}$ levels across the day were best fit by a quadratic trend in both PD and HC subjects. CSF TNF has the clearest pattern of change across the day, increasing from below $1 \mathrm{pg} / \mathrm{mL}$ at 5:30 AM to around $2 \mathrm{pg} / \mathrm{mL}$ at around 11:30 $\mathrm{AM}$ and finally back down to below $1 \mathrm{pg} / \mathrm{mL}$ at 5:30 AM the next 
day. However, there was no difference in CSF TNF levels between $\mathrm{PD}$ and $\mathrm{HC}$ subjects at any time point, and the lack of significant quadratic trend in HC CSF TNF is likely due to a small sample size. Although few studies have sampled biofluids across the day to determine diurnal inflammatory patterns, one study in adult insomnia patients and age-matched HCs $(\sim 27-31$ years old $)$ found disturbed rhythms in plasma IL-6 and increased plasma TNF (but no diurnal rhythm) in insomniacs, when measured every $30 \mathrm{~min}$ across $24 \mathrm{~h}$ [74]. Although we have no information on the extent of sleep disruption in subjects participating in this study, we noted a decrease in serum TNF with disease, we similarly noted stable TNF levels across the day in PD and HC subjects and found similar levels of IL- 6 and TNF in our 50year old subjects $(\sim 3-6 \mathrm{pg} / \mathrm{ml}$ and $\sim 2-3 \mathrm{pg} / \mathrm{ml}$, respectively). While we did not find significant rhythmicity in serum IL-6 across the day, this could be due to our small sample size as the plasma IL- 6 pattern noted by Vgontzas and colleagues [74] bears striking resemblance to what we noted for serum IL-6 with a more robust increase and then apparent decrease across the day in PD subjects and insomniacs versus $\mathrm{HC}$ subjects whom displayed a relatively flat profile across the day in both studies [74]. Additionally, our data confirm previous reports demonstrating rhythmicity in CSF $A \beta_{40}$ and $A \beta_{42}$ across the day [75]. Together, these data suggest that there is more variability in central inflammation across the day in PD subjects as compared with HCs. Cytokines and other proteins (including cortisol) are significantly increased after knee surgery, and rise and fall more in the CSF than in the serum, indicating that increased fluctuation of CSF proteins as compared to serum levels is not uncommon [76]. One reason could be due to the relatively low dilution of cytokines by CSF versus the much higher volume of the blood circulatory system, and Bromander et al. speculate that the greater fluctuation seen in CSF versus serum could be because the inflammatory systems of the brain and the periphery are regulated separately, and suggest that CSF cytokine fluctuation may indicate BBB disruption, a characteristic known to be associated with neurodegenerative disease [77].

Though serum and CSF inflammatory factors have been suggested to reflect one another, there are conflicting reports [28]. Therefore, we investigated the relationship between serum and CSF levels of all detectable analytes in $\mathrm{HC}$ and $\mathrm{PD}$ subjects across the day and found that levels of IL- 6 and CRP covary in serum and CSF across the day, and they do so in a diseasedependent manner. Surprisingly, we found that of all analytes evaluated at time 0 , CRP is the one inflammatory factor in serum that reflects levels in CSF (although concentration ranges are an order of magnitude lower in
CSF). While we demonstrated no difference between serum or CSF CRP between HC and PD subjects, CRP has been reported to be associated with increased risk of death and indicative of life expectancy in PD subjects [78]. These discrepancies could be accounted for by individual variability, as there was substantial withinsubject variability in serum and CSF CRP across the 24-h sampling period. Interestingly, while CRP levels were variable across the day in the serum and CSF of the majority of PD subjects, CSF CRP levels were stable in the majority of $\mathrm{HC}$ subjects, indicating that diurnal patterns of CSF CRP may be disrupted in association with PD. These important findings suggest that blood analysis of CRP could feasibly be used to probe neuroinflammation to inform inflamm-aging [79-81] or disease status without a need for the more invasive lumbar catheter puncture for CSF collection. Additionally, mechanism-based hypotheses about neuroinflammatory status may be gleaned from analyzing existing data on serum CRP levels in PD subjects.

Alpha ( $\alpha$ )-synuclein, Amyloid-beta-40 $\left(\mathrm{A} \beta_{40}\right)$, and $A \beta_{42}$ are proteins currently under intense investigation as potential biomarkers of neurodegenerative disease. Levels of inflammatory factors in the brain are likely to be changing prior to frank neuronal death because microglia, the innate immune cells in the brain produce cytokines when activated in response to aggregated proteins $[1,82]$. A wealth of evidence indicates that toxic oligomers of $\alpha$-synuclein and $A \beta$ peptides trigger inflammatory responses in vitro and in vivo and compromise neuronal health and survival [83-85] and that brain inflammation, in turn, increases aggregation of those oligomers [25, 86-88]. Our data demonstrate that, across time, serum IFN $\gamma$, serum CRP, CSF TNF, and CSF CRP covary with all three biomarkers of neurodegenerative disease $\left(\alpha\right.$-synuclein, $A \beta_{40}$, and $\left.A \beta_{42}\right)$ in a diseasedependent manner. These exciting and novel data suggest that serum and CSF inflammation may be associated with abnormalities in CSF levels of $\alpha$-synuclein, $A \beta_{40}$, and $A \beta_{42}$. Interestingly, all significant relationships between CSF and serum inflammation and CSF toxic peptide levels at time 0 are positive such that as inflammation in CSF or periphery increases, so do CSF $\alpha$ synuclein and $A \beta$ peptides, providing additional evidence that inflammation and toxic oligomer species may be part of a feed-forward cycle of protein aggregationneuroinflammation.

The Unified Parkinson's Disease Rating Scale (UPDRS) is comprised of several components including the mentation, behavior, and mood score, the activities of daily living score (ADL), the motor evaluation score, and the complications of therapy score. Our data indicate that serum IL-8 levels were significantly and positively associated with the ADL scores component of the UPDRS. 
As serum IL-8 was stable across the day in the majority of PD individuals, this factor may be of interest in future longitudinal studies to determine whether it is associated with disease severity irrespective of disease duration or time of day. Consistent with this idea, the association of IL-8 with clinical severity was also reported in a recent analysis of human serum in a multi-center cohort of 142 subjects with familial PD arising from leucine rich repeat kinase 2 (LRRK2) mutations where high levels of IL-8, MCP-1, and CCL4 were associated with the presence of a specific clinical subtype that is characterized by a broad and more severely affected spectrum of motor and nonmotor symptoms [89]. With regards to inflammatory markers in the CSF, IFNy levels were higher in PD individuals with higher UPDRS total scores, higher activities of daily living (ADL) scores, and in PD individuals that have more complications from therapeutic treatment, suggesting that IFNY levels may be of particular interest in disease staging and monitoring. IFN $\gamma$ regulates the expression of major histocompatibility complex II (MHCII) on monocytes, microglia, and macrophages [90]. A single nucleotide polymorphism located in the first intron of the MHCII Human Leukocyte Antigen (HLA)-DRA gene was found to be significantly associated with sporadic PD in a recent genome wide association study [91], indicating that IFNy may contribute to disease severity by affecting antigen presentation and the resulting inflammatory response. Finally, increased expression of IFN $\gamma$ in the CNS driven by a viral vector in mouse brain resulted in basal ganglia calcification and nigrostriatal degeneration, reminiscent of human idiopathic basal ganglia calcification (IBGC) [63].

Given that PD is an extremely heterogeneous disease with differing rates of progression [35, 92], our results demonstrating that inflammation did not increase with years since PD diagnosis are not entirely surprising. Indeed, these findings are in line with imaging data demonstrating increased inflammation in the pons, basal ganglia, striatum, and cortex of PD subjects irrespective of disease duration [13], lending credence to the hypothesis that changes in inflammation likely occur early in disease and remain present throughout the course of disease. One additional potential reason for the finding that these inflammatory markers positively correlate with some measures of PD severity but not duration is the fact that the biofluids analyzed in this study were taken from a MJFF repository originating from an experimental medicine study that selected subjects able to tolerate the continuous CSF procedures. Therefore, it is a subset of the PD population (usually younger) and therefore with shorter duration of illness. However, severity of $\mathrm{PD}$ in this population might well be related to individuals with more aggressive deterioration and therefore linked to inflammatory biomarkers. The potential value of inflammatory biomarker assessment is in its predictive ability in identifying who is likely to have a faster rate of decline despite years with disease. The key to resolving this issue is to replicate the findings in a larger cohort of subjects.

We used linear discriminant analysis (LDA) to determine if any particular analyte or set of analytes allowed for correct assignment of any one sample to PD or HC group membership across time. To our surprise, there was a relatively minimal misclassification when only serum TNF levels were considered; serum TNF alone misclassified, at most, only $25 \%$ of PD subjects (3 of 12) into the HC group, and 33\% of HC (2 of 6) subjects into the PD group across all time points. When serum TNF and CSF $\alpha$-synuclein levels are considered together, $\geq 82 \%$ sensitivity and $83 \%$ specificity were achieved in both $\mathrm{HC}$ and $\mathrm{PD}$ groups across all time points; CSF tau and $A \beta$ demonstrate comparable sensitivity (but less specificity) as diagnostic tools for Alzheimer's disease [93]. Together, these analyses indicate that, at a minimum, TNF measured in the serum and $\alpha$-synuclein measured in the CSF have high potential utility for sensitive and specific detection of PD state.

\section{Conclusions}

In summary, our data indicate that serum and CSF NGAL, TNF, IFN $\gamma$, and CRP, and serum IFN $\gamma$ are promising candidate biomarkers of inflammation. Importantly, we emphasize that the sample size in our study was very small and confirmatory studies will be needed in a larger cohort of subjects to validate these findings using current biorepositories with banked serum and CSF, details regarding the employed collection protocol, and good clinical history data for each subject (such as in the PPMI, Precept/PROBE and HBS cohorts [94] as well as in the DeNoPa cohort [44]), including information about autoimmune and chronic systemic disease (diabetes, obesity, cardiovascular disease, etc.) and other comorbidities that could influence the levels of inflammatory proteins in their biofluids. In the future, we propose that a similar 24-h collection study should be performed in subjects experiencing prodromal pre-motor symptoms of PD to investigate the extent to which the factors we identified could be used to aid in earlier diagnosis of individuals at risk and to monitor their disease trajectory, and hope that the data reported in this small study will generate hypotheses regarding potential inflammatory profiles in patients with neurodegenerative disease. 


\section{Additional files}

Additional file 1: Regression analysis of each analyte by individual and means and SEM by analyte across time. (PDF $1526 \mathrm{~kb}$ )

Additional file 2: Serum TNF and NGAL are significantly different between PD and HC at time 0. (PDF $561 \mathrm{~kb}$ )

Additional file 3: Serum TNF, IFNy, and NGAL are different between PD and $\mathrm{HC}$ irrespective of time. (PDF $1693 \mathrm{~kb}$ )

Additional file 4: $\mathrm{PD}$ and $\mathrm{HC}$ subjects have different relationships between serum and CSF inflammation. (PDF $801 \mathrm{~kb}$ )

Additional file 5: Summary of relationships between inflammation and Aßs and a-synuclein in PD and HC. (PDF 2346 kb)

Additional file 6: Serum and CSF CRP levels are positively correlated in $\mathrm{HC}$ and PD at baseline. The relationship between serum and CSF inflammatory factors was analyzed using samples from the first collection period (baseline; time 0). There was no significant correlation between serum and CSF levels of any factor except CRP (a). Serum and CSF CRP significantly correlate in $\mathrm{HC}$ (slope $\left.=325 \pm 86.9, F_{(1,4)}=14.0 ; p=0.02\right)$ and in PD (slope $=415.5 \pm 26.6, F_{(1,10)}=243.8 ; p<0.0001$ ), but the slopes do not differ between HC and PD $(t(16)=1.28 ; p=0.22)$. Serum and CSF $\mathrm{NGAL}\left(\mathrm{HC} ;\right.$ slope $=66.57 \pm 64.63, R^{2}=0.17, F_{(1.4)}=0.80 ; p=0.42$ and PD; slope $\left.=3.44 \pm 18.28, R^{2}=0.003, F_{(1,10)}=0.04 ; p=0.85\right)(b)$, TNF (HC; slope $=-0.33 \pm 0.40, R^{2}=0.15, F_{(1,4)}=0.68 ; p=0.46$ and PD; slope $=2.15 \pm 2.13$, $\left.R^{2}=0.09, F_{(1,10)}=1.02 ; p=0.34\right)(\mathrm{c}), \mathrm{IL}-6$ (HC; slope $=-0.05 \pm 0.09, R^{2}=0.07$ $F_{(1,4)}=0.32 ; p=0.60$ and $P D$; slope $=-0.03 \pm 0.11, R^{2}=0.009, F_{(1,10)}=0.09$; $p=0.77)(\mathrm{d}), \mathrm{IL}-8\left(\mathrm{HC} ;\right.$ slope $=0.20 \pm 0.17, R^{2}=0.25, F_{(1.4)}=1.31 ; p=0.32$ and PD; slope $\left.=0.06 \pm 0.22, R^{2}=0.01, F_{(1,10)}=0.08 ; p=0.79\right)(e)$, and IFNY $\left(H C\right.$; slope $=-5.64 \pm 4.78, R^{2}=0.28, F_{(1.4)}=1.59 ; p=0.28$ and PD; slope $=9.42 \pm 12.77, R^{2}=0.05, F_{(1,10)}=0.54 ; p=0.48$ ) (f) do not correlate at baseline. (PDF $74 \mathrm{~kb}$ )

Additional file 7: Baseline CSF a-synuclein and ABs and CSF and serum inflammatory proteins between PD and HCs. (PDF 1977 kb)

Additional file 8: CSF IFNY and serum IL-8 positively correlated with UPDRS components at baseline in PD subjects. (PDF $563 \mathrm{~kb}$ )

Additional file 9: Linear discriminant analysis reveals sensitivity and selectivity of analytes in discriminating between $\mathrm{HC}$ and PD. Serum and CSF levels of IL-6 (a), serum IL-6 (b). Serum and CSF IL-8, TNF, NGAL, and IFNY, and CSF a-synuclein, $A \beta 40$ and $A \beta 42$ (d), serum IL-8, TNF, NGAL, IFNy, and CSF a-synuclein, A 440 , and $A \beta 42$ (e), serum and CSF IL-8, TNF, NGAL, IFNY, and CSF AB40 (f), serum and CSF IL-8, TNF, NGAL, IFNY, and CSF AB42 (g), serum and CSF IL-8, TNF, NGAL, IFNY, and CSF a-synuclein (h), serum and CSF IL-8, TNF, NGAL, IFNY (i), serum IL-8, TNF, NGAL, IFNy, and CSF A 442 (j), serum IL-8, TNF, NGAL, IFNy, and CSF a-synuclein (k), serum IL-8, TNF, NGAL, IFNY, and CSF A 40 (I), serum and CSF TNF, NGAL, IFNY, and CSF asynuclein, $A \beta 40$, and $A \beta 42(m)$, serum TNF, NGAL, IFNy, and CSF a-synuclein, and $A \beta 42(n)$, serum TNF, NGAL, and IFNY (o), serum and CSF TNF, NGAL, and IFNY (p), serum TNF, NGAL, and IFNy and CSF a-synuclein, $A \beta 40$, and $A \beta 42$ (q), serum TNF and CSF a-synuclein, and A 42 ( $r$ ), serum TNF and CSF $A \beta 42(\mathrm{~s})$, serum IL-8, TNF, NGAL, and IFNy (t). The $x$ axis is the percentage of correct categorization into a group, and the red line is set at the lowest percentage of correct categorizations for the factor or factors considered. The $y$ axis is the collection hour. (PDF $239 \mathrm{~kb}$ )

Additional file 10: Subject demographics. (PDF $411 \mathrm{~kb}$ )

Additional file 11: Inclusion and exclusion criteria summary. (PDF $1759 \mathrm{~kb}$ )

\section{Abbreviations}

ADLS: Activities of daily living score; ANCOVA: Analysis of covariance; ANOVA: Analysis of variance; $A \beta$ : Amyloid $\beta ; A \beta_{40}$ : $\beta$-Amyloid 1-40; $A \beta_{42}$ : $\beta$-Amyloid 1-42; BCA: Bicinchoninic acid assay; BMl: Body mass index; CCL4: Chemokine (C-C motif) ligand 4; CNS: Central nervous system; CRP: C-reactive protein; CSF: Cerebrospinal fluid; CV: Coefficient of variation; DA: Dopamine; ECG: Electrocardiogram; ECL: Electrochemiluminescent; ELISA: Enzyme-linked immunosorbent assay; H\&Y: Hoehn and Yahr; HC: Age-matched healthy controls; HIV: Human immunodeficiency virus; HLA-DRA: Human leukocyte antigen - DR a chain; IBGC: Idiopathic basal ganglia calcification; IFNY : Interferon $\gamma$; IL: Interleukin; LDA: Linear discriminant analysis; L-DOPA: L-3,4-dihydroxyphenylalanine;
LRRK2: Leucine rich repeat kinase 2; MAO-B: Monoamine oxidase B; MCP-1: Monocyte chemoattractant protein-1; MHCll: Major histocompatibility complex II; MJFF: Michael J. Fox Foundation; MSD: ELISA Meso Scale Discovery; NFkB: Nuclear factor kappa B; NGAL: Neutrophil gelatinaseassociated lipocalin; PD: Parkinson's disease; PI: Primary investigator; RBC: Red blood cell; SEM: Standard error of the mean; TNF: Tumor necrosis factor; UPDRS: Unified Parkinson's Disease Rating Scale; aSyn: a-Synuclein

\section{Acknowledgements}

We thank the patients and subject volunteers for participating in this study and staff at California Clinical Trials Medical Group for conducting this study (LE, MY). We thank the Tansey Lab for useful discussions. The content is solely the responsibility of the authors and does not necessarily reflect the official views of the National Institutes of Health.

\section{Funding}

This study was supported in part by The Michael J. Fox Foundation for Parkinson's Research 24-Hour Biofluids (MGT) and Assay Development (BM, PT) Programs, the National Institutes of Health/National Institute of Neurological Disorders and Stroke NRSA Fellowship F31 NS081830-02 (GTK) and the Emory Multiplexed Immunoassay Core (EMIC), which is subsidized by the Emory University School of Medicine and is one of the Emory Integrated Core Facilities. Additional support was provided by the National Center for Advancing Translational Sciences of the National Institutes of Health under award number UL1TR000454.

\section{Availability of data and materials}

The datasets used and/or analyzed during the current study are available from the corresponding author on reasonable request.

\section{Authors' contributions}

LNE aided in designing study questions, analyzing and interpreting data, and was primarily responsible for writing the manuscript. GTK and CJB aided in designing study questions and interpreting data. JJC and JC ran ELISA MSD assays. CCG, PT, BM, MGS, LE, MY, CK, MF, KM, and VSH conducted complex data analysis and interpretation, and $\mathrm{MGT}^{*}$ aided in designing study, interpreting data, and manuscript writing. All authors read and approved the final manuscript.

\section{Ethics approval and consent to participate}

All relevant study documentation was reviewed and approved by the responsible Institutional Review Board (IRB; Aspire IRB, 11,491 Woodside Avenue, Santee, California 92,071, USA). All subjects were informed of the nature and purpose of the study and provided written informed consent during pre-study screening.

\section{Consent for publication}

Not applicable.

\section{Competing interests}

The authors declare that they have no competing interests.

\section{Publisher's Note}

Springer Nature remains neutral with regard to jurisdictional claims in published maps and institutional affiliations.

\section{Author details}

'Department of Physiology, Emory University, 615 Michael Street, 605L Whitehead Biomedical Res. Bldg., Atlanta, GA 30322, USA. ²Department of Biostatistics, University of lowa, 145 N. Riverside Drive, 100 CPHB, lowa City, lowa 52242, USA. ${ }^{3}$ BioLegend, Inc., 180 Rustcraft Rd \# 140, Dedham, Massachusetts 02026, USA. ${ }^{4}$ Paracelsus-Elena-Klinik, 34128 Kassel, Kassel, Germany. ${ }^{5}$ Georg-August University Medical Center Goettingen, 37075 Goettingen, Germany. ${ }^{6}$ Program in Neuroscience and Division of Neurology, The Ottawa Hospital, University of Ottawa Brain \& Mind Institute, 451 Smyth Road, Room 1412, Ottawa K1H 8M5, Canada. ${ }^{7}$ Follow the Molecule, 143 Voyage Mall, Marina del Rey, CA 90292, USA. ${ }^{8}$ PAREXEL International, Early Phase Unit, 1560 E. Chevy Chase Drive, Suite 140, Glendale, CA 91206, USA. ${ }^{9}$ Research Programs, The Michael J. Fox Foundation for Parkinson's Research, 69 7th Avenue, 498, New York, NY 10018, USA. ${ }^{10}$ Yale-New Haven Hospital, 20 York Street, New Haven, CT 06510, USA. ${ }^{11}$ Nell Hodgson Woodruff School of Nursing, Emory University, 1520 Clifton Rd, Atlanta, GA 30322, USA. 
Received: 23 May 2017 Accepted: 7 August 2017

\section{Published online: 18 August 2017}

\section{References}

1. Ransohoff RM. How neuroinflammation contributes to neurodegeneration. Science. 2016:353:777-83.

2. Joers V, Tansey MG, Mulas G, Carta AR. Microglial phenotypes in Parkinson's disease and animal models of the disease. Prog Neurobiol. 2016;155:57-75

3. Kannarkat GT, Boss JM, Tansey MG. The role of innate and adaptive immunity in Parkinson's disease. J Park Dis. 2013;3:493-514.

4. Chen L, Mo M, Li G, Cen L, Wei L, Xiao Y, Chen X, Li S, Yang X, Qu S, Xu P. The biomarkers of immune dysregulation and inflammation response in Parkinson disease. Trans Neurodegeneration. 2016;5:16.

5. Brockmann K, Apel A, Schulte C, Schneiderhan-Marra N, Pont-Sunyer C, Vilas D, Ruiz-Martinez J, Langkamp M, Corvol JC, Cormier F, et al. Inflammatory profile in LRRK2-associated prodromal and clinical PD. J Neuroinflammation. 2016;13:122.

6. Kang JH. Cerebrospinal fluid amyloid beta1-42, tau, and alpha-synuclein predict the heterogeneous progression of cognitive dysfunction in Parkinson's disease. J Mov Disord. 2016;9:89-96.

7. Mollenhauer B, Zimmermann J, Sixel-Doring F, Focke NK, Wicke T, Ebentheuer J, Schaumburg M, Lang E, Trautmann E, Zetterberg $H$, et al. Monitoring of 30 marker candidates in early Parkinson disease as progression markers. Neurology. 2016;87:168-77.

8. Cornejo F, von Bernhardi R. Age-dependent changes in the activation and regulation of microglia. Adv Exp Med Biol. 2016;949:205-26.

9. McGeer PL, Itagaki S, Boyes BE, McGeer EG. Reactive microglia are positive for HLA-DR in the substantia nigra of Parkinson's and Alzheimer's disease brains. Neurology. 1988;38:1285-91.

10. Hirsch EC, Hunot S. Neuroinflammation in Parkinson's disease: a target for neuroprotection? Lancet Neurol. 2009:8:382-97.

11. Mogi M, Togari A, Kondo T, Mizuno Y, Komure O, Kuno S, Ichinose H, Nagatsu T. Caspase activities and tumor necrosis factor receptor R1 (p55) level are elevated in the substantia nigra from parkinsonian brain. J Neural Transm. 2000;107:335-41.

12. Mogi M, Kondo T, Mizuno Y, Nagatsu T. p53 protein, interferon-gamma, and NF-kappaB levels are elevated in the parkinsonian brain. Neurosci Lett. 2007; 414:94-7.

13. Gerhard A, Pavese N, Hotton G, Turkheimer F, Es M, Hammers A, Eggert K, Oertel W, Banati RB, Brooks DJ. In vivo imaging of microglial activation with [11C](R)PK11195 PET in idiopathic Parkinson's disease. Neurobiol Dis. 2006;21:404-12.

14. Gerhard A. TSPO imaging in parkinsonian disorders. Clin Trans Imaging. 2016:4:183-90.

15. Terada T, Yokokura M, Yoshikawa E, Futatsubashi M, Kono S, Konishi T, Miyajima H, Hashizume T, Ouchi Y. Extrastriatal spreading of microglial activation in Parkinson's disease: a positron emission tomography study. Ann Nucl Med. 2016;30:579-87.

16. Czlonkowska A, Kohutnicka M, Kurkowska-Jastrzebska I, Czlonkowski A. Microglial reaction in MPTP (1-methyl-4-phenyl-1,2,3,6-tetrahydropyridine) induced Parkinson's disease mice model. Neurodegeneration. 1996;5:137-43.

17. Kurkowska-Jastrzebska I, Wronska A, Kohutnicka M, Czlonkowski A, Czlonkowska A. MHC class II positive microglia and lymphocytic infiltration are present in the substantia nigra and striatum in mouse model of Parkinson's disease. Acta Neurobiol Exp. 1999;59:1-8.

18. Castano A, Herrera AJ, Cano J, Machado A. Lipopolysaccharide intranigral injection induces inflammatory reaction and damage in nigrostriatal dopaminergic system. J Neurochem. 1998;70:1584-92.

19. Castano A, Herrera AJ, Cano J, Machado A. The degenerative effect of a single intranigral injection of LPS on the dopaminergic system is prevented by dexamethasone, and not mimicked by rh-TNF-alpha, IL-1beta and IFNgamma. J Neurochem. 2002;81:150-7.

20. Kohutnicka M, Lewandowska E, Kurkowska-Jastrzebska I, Czlonkowski A, Czlonkowska A. Microglial and astrocytic involvement in a murine model of Parkinson's disease induced by 1-methyl-4-phenyl-1,2,3,6-tetrahydropyridine (MPTP). Immunopharmacology. 1998;39:167-80.

21. Herrera AJ, Castano A, Venero JL, Cano J, Machado A. The single intranigral injection of LPS as a new model for studying the selective effects of inflammatory reactions on dopaminergic system. Neurobiol Dis. 2000;7:429-47.

22. Cao JP, Wang HJ, Yu JK, Liu HM, Gao DS. The involvement of NF-kappaB p65/p52 in the effects of GDNF on DA neurons in early PD rats. Brain Res Bull. 2008;76:505-11.
23. Gao JP, Sun S, Li WW, Chen YP, Cai DF. Triptolide protects against 1-methyl4-phenyl pyridinium-induced dopaminergic neurotoxicity in rats: implication for immunosuppressive therapy in Parkinson's disease. Neurosci Bull. 2008; 24:133-42.

24. Gao X, Hu X, Qian L, Yang S, Zhang W, Zhang D, Wu X, Fraser A, Wilson B, Flood PM, et al. Formyl-methionyl-leucyl-phenylalanine-induced dopaminergic neurotoxicity via microglial activation: a mediator between peripheral infection and neurodegeneration? Environ Health Perspect. 2008;116:593-8.

25. Sanchez-Guajardo V, Barnum CJ, Tansey MG, Romero-Ramos M. Neuroimmunological processes in Parkinson's disease and their relation to alpha-synuclein: microglia as the referee between neuronal processes and peripheral immunity. ASN Neuro. 2013;5:113-39.

26. Tansey MG, Goldberg MS. Neuroinflammation in Parkinson's disease: its role in neuronal death and implications for therapeutic intervention. Neurobiol Dis. 2010;37:510-8.

27. Atkins HL, Bowman M, Allan D, Anstee G, Arnold DL, Bar-Or A, BenceBruckler I, Birch P, Bredeson C, Chen J, et al. Immunoablation and autologous haemopoietic stem-cell transplantation for aggressive multiple sclerosis: a multicentre single-group phase 2 trial. Lancet. 2016;388:576-85.

28. Qin XY, Zhang SP, Cao C, Loh YP, Cheng Y. Aberrations in peripheral inflammatory cytokine levels in Parkinson disease: a systematic review and meta-analysis. JAMA Neurol. 2016;

29. Boka G, Anglade P, Wallach D, Javoy-Agid F, Agid Y, Hirsch EC. Immunocytochemical analysis of tumor necrosis factor and its receptors in Parkinson's disease. Neurosci Lett. 1994;172:151-4.

30. Mogi M, Harada M, Kondo T, Riederer P, Inagaki H, Minami M, Nagatsu T. Interleukin-1 beta, interleukin-6, epidermal growth factor and transforming growth factor-alpha are elevated in the brain from parkinsonian patients. Neurosci Lett. 1994;180:147-50.

31. Mogi M, Harada M, Narabayashi $H$, Inagaki H, Minami M, Nagatsu T. Interleukin (IL)-1 beta, IL-2, IL-4, IL-6 and transforming growth factor-alpha levels are elevated in ventricular cerebrospinal fluid in juvenile parkinsonism and Parkinson's disease. Neurosci Lett. 1996;211:13-6.

32. Mogi M, Harada M, Riederer $P$, Narabayashi H, Fujita K, Nagatsu T. Tumor necrosis factor-alpha (TNF-alpha) increases both in the brain and in the cerebrospinal fluid from parkinsonian patients. Neurosci Lett. 1994;165:208-10.

33. Brodacki B, Staszewski J, Toczylowska B, Kozlowska E, Drela N, Chalimoniuk M, Stepien A. Serum interleukin (IL-2, IL-10, IL-6, IL-4), TNFalpha, and INFgamma concentrations are elevated in patients with atypical and idiopathic parkinsonism. Neurosci Lett. 2008;441:158-62.

34. Gruden MA, Yanamandra K, Kucheryanu VG, Bocharova OR, Sherstnev W, Morozova-Roche LA, Sewell RD. Correlation between protective immunity to alpha-synuclein aggregates, oxidative stress and inflammation. Neuroimmunomodulation. 2012;19:334-42.

35. Williams-Gray CH, Wijeyekoon R, Yarnall AJ, Lawson RA, Breen DP, Evans JR, Cummins GA, Duncan GW, Khoo TK, Burn DJ, Barker RA. Serum immune markers and disease progression in an incident Parkinson's disease cohort (ICICLE-PD). Mov Dis. 2016;31:995-1003.

36. Hu Y, Yu SY, Zuo LJ, Cao CJ, Wang F, Chen ZJ, Du Y, Lian TH, Wang YJ, Chan $P$, et al. Parkinson disease with REM sleep behavior disorder: features, alpha-synuclein, and inflammation. Neurology. 2015;84:888-94.

37. Koziorowski D, Tomasiuk R, Szlufik S, Friedman A. Inflammatory cytokines and NT-proCNP in Parkinson's disease patients. Cytokine. 2012;60:762-6.

38. Gupta V, Garg RK, Khattri S. Levels of IL-8 and TNF-alpha decrease in Parkinson's disease. Neurol Res. 2016;38:98-102.

39. Fries $E$, Dettenborn $L$, Kirschbaum $C$. The cortisol awakening response (CAR): facts and future directions. Int J Psychophysiol. 2009;72:67-73.

40. Coyle PK. Glucocorticoids in central nervous system bacterial infection. Arch Neurol. 1999;56:796-801.

41. Chao CC, Hu S, Close K, Choi CS, Molitor TW, Novick WJ, Peterson PK. Cytokine release from microglia: differential inhibition by pentoxifylline and dexamethasone. J Infect Dis. 1992;166:847-53.

42. Hughes AJ, Daniel SE, Kilford L, Lees AJ. Accuracy of clinical diagnosis of idiopathic Parkinson's disease: a clinico-pathological study of 100 cases. J Neurol Neurosurg Psychiatry. 1992;55:181-4.

43. Ereshefsky L, Frasier M, Yen M, Jhee S, Marek K, Taylor P, Sherman M, Caspell C, Coffey C, Schlossmacher M, Sherer T. Diurnal and inter-subject variability of cerebrospinal fluid biomarkers, $A \beta-40 / 42$, alpha-synuclein and DJ-1 in healthy volunteers and Parkinson's patients. In: 11 th international conference on Alzheimer's \& Parkinson's disease (AD/PD); Florence, Italy; 2013. 
44. Mollenhauer B, Trautmann E, Taylor P, Manninger P, Sixel-Doring F, Ebentheuer J, Trenkwalder C, Schlossmacher MG. Total CSF alpha-synuclein is lower in de novo Parkinson patients than in healthy subjects. Neurosci Lett. 2013:532:44-8.

45. Bessler H, Djaldetti R, Salman H, Bergman M, Djaldetti M. IL-1 beta, IL-2, IL-6 and TNF-alpha production by peripheral blood mononuclear cells from patients with Parkinson's disease. Biomed Pharmacother. 1999;53:141-5.

46. Bortolanza M, Cavalcanti-Kiwiatkoski R, Padovan-Neto FE, Da-Silva CA, Mitkovski M, Raisman-Vozari R, Del-Bel E. Glial activation is associated with IDOPA induced dyskinesia and blocked by a nitric oxide synthase inhibitor in a rat model of Parkinson's disease. Neurobiol Dis. 2015;73:377-87.

47. Bortolanza M, Padovan-Neto FE, Cavalcanti-Kiwiatkoski R, Dos Santos-Pereira M, Mitkovski M, Raisman-Vozari R, Del-Bel E. Are cyclooxygenase-2 and nitric oxide involved in the dyskinesia of Parkinson's disease induced by L-DOPA? Philos Trans R Soc Lond Ser B Biol Sci. 2015;370

48. Felger JC, Hernandez CR, Miller AH. Levodopa reverses cytokine-induced reductions in striatal dopamine release. Int J Neuropsychopharmacol. 2015;18

49. Rocha NP, Assis F, Scalzo PL, Vieira EL, Barbosa IG, de Souza MS, Christo PP, Reis HJ, Teixeira AL. Reduced activated T lymphocytes (CD4+CD25+) and plasma levels of cytokines in Parkinson's disease. Mol Neurobiol. 2017;

50. Gangemi S, Basile G, Merendino RA, Epifanio A, Di Pasquale G, Ferlazzo B, Nicita-Mauro V, Morgante L. Effect of levodopa on interleukin-15 and RANTES circulating levels in patients affected by Parkinson's disease. Mediat Inflamm. 2003;12:251-3.

51. Hohagen F, Timmer J, Weyerbrock A, Fritsch-Montero R, Ganter U, Krieger S, Berger M, Bauer J. Cytokine production during sleep and wakefulness and its relationship to cortisol in healthy humans. Neuropsychobiology. 1993;28: 9-16.

52. Lee M, Tazzari V, Giustarini D, Rossi R, Sparatore A, Del Soldato P, McGeer E, McGeer PL. Effects of hydrogen sulfide-releasing L-DOPA derivatives on glial activation: potential for treating Parkinson disease. J Biol Chem. 2010;285: 17318-28.

53. Li J, Llano DA, Ellis T, LeBlond D, Bhathena A, Jhee SS, Ereshefsky L, Lenz R, Waring JF. Effect of human cerebrospinal fluid sampling frequency on amyloid-beta levels. Alzheimers Dement. 2012;8:295-303.

54. McCoy MK, Martinez TN, Ruhn KA, Szymkowski DE, Smith CG, Botterman BR, Tansey KE, Tansey MG. Blocking soluble tumor necrosis factor signaling with dominant-negative tumor necrosis factor inhibitor attenuates loss of dopaminergic neurons in models of Parkinson's disease. J Neurosci. 2006;26: 9365-75.

55. McCoy MK, Ruhn KA, Martinez TN, McAlpine FE, Blesch A, Tansey MG. Intranigral lentiviral delivery of dominant-negative TNF attenuates neurodegeneration and behavioral deficits in hemiparkinsonian rats. Mol Ther. 2008;16:1572-9.

56. Tran TA, McCoy MK, Sporn MB, Tansey MG. The synthetic triterpenoid CDDOmethyl ester modulates microglial activities, inhibits TNF production, and provides dopaminergic neuroprotection. J Neuroinflammation. 2008;5:14

57. Harms AS, Barnum CJ, Ruhn KA, Varghese S, Trevino I, Blesch A, Tansey MG. Delayed dominant-negative TNF gene therapy halts progressive loss of nigral dopaminergic neurons in a rat model of Parkinson's disease. Mol Ther. 2011;19:46-52

58. Barnum CJ, Chen X, Chung J, Chang J, Williams M, Grigoryan N, Tesi RJ, Tansey MG. Peripheral administration of the selective inhibitor of soluble tumor necrosis factor (TNF) XPro(R)1595 attenuates nigral cell loss and glial activation in 6-OHDA hemiparkinsonian rats. J Park Dis. 2014;4:349-60.

59. Leng A, Mura A, Feldon J, Ferger B. Tumor necrosis factor-alpha receptor ablation in a chronic MPTP mouse model of Parkinson's disease. Neurosci Lett. 2005:375:107-11.

60. Sriram K, Matheson JM, Benkovic SA, Miller DB, Luster MI, O'Callaghan JP. Mice deficient in TNF receptors are protected against dopaminergic neurotoxicity: implications for Parkinson's disease. FASEB J. 2002;16:1474-6.

61. Sriram K, Matheson JM, Benkovic SA, Miller DB, Luster MI, O'Callaghan JP. Deficiency of TNF receptors suppresses microglial activation and alters the susceptibility of brain regions to MPTP-induced neurotoxicity: role of TNFalpha. FASEB J. 2006;20:670-82.

62. Ferger B, Leng A, Mura A, Hengerer B, Feldon J. Genetic ablation of tumor necrosis factor-alpha (TNF-alpha) and pharmacological inhibition of TNFsynthesis attenuates MPTP toxicity in mouse striatum. J Neurochem. 2004; 89:822-33.

63. Chakrabarty P, Ceballos-Diaz C, Lin WL, Beccard A, Jansen-West K, McFarland NR, Janus C, Dickson D, Das P, Golde TE. Interferon-gamma induces progressive nigrostriatal degeneration and basal ganglia calcification. Nat Neurosci. 2011;14:694-6.

64. Lindqvist D, Kaufman E, Brundin L, Hall S, Surova Y, Hansson O. Non-motor symptoms in patients with Parkinson's disease--correlations with inflammatory cytokines in serum. PLoS One. 2012;7:e47387.

65. Flower DR. The lipocalin protein family: structure and function. Biochem J. 1996;318(Pt 1):1-14.

66. Goetz DH, Holmes MA, Borregaard N, Bluhm ME, Raymond KN, Strong RK. The neutrophil lipocalin NGAL is a bacteriostatic agent that interferes with siderophore-mediated iron acquisition. Mol Cell. 2002;10:1033-43.

67. Naude PJ, Nyakas C, Eiden LE, Ait-Ali D, van der Heide R, Engelborghs , Luiten PG, De Deyn PP, den Boer JA, Eisel UL. Lipocalin 2: novel component of proinflammatory signaling in Alzheimer's disease. FASEB J. 2012;26:2811-23.

68. Sousa MM, do Amaral JB, Guimaraes A, Saraiva MJ. Up-regulation of the extracellular matrix remodeling genes, biglycan, neutrophil gelatinaseassociated lipocalin, and matrix metalloproteinase-9 in familial amyloid polyneuropathy. FASEB J. 2005;19:124-6.

69. Naude PJ, Eisel UL, Comijs HC, Groenewold NA, De Deyn PP, Bosker FJ, Luiten PG, den Boer JA, Oude Voshaar RC. Neutrophil gelatinaseassociated lipocalin: a novel inflammatory marker associated with latelife depression. J Psychosom Res. 2013;75:444-50.

70. Marijnissen RM, Naude PJ, Comijs HC, Schoevers RA, Oude Voshaar RC. Waist circumference and neutrophil gelatinase-associated lipocalin in late-life depression. Brain Behav Immun. 2014;37:231-9.

71. Naude PJ, den Boer JA, Comijs HC, Bosker FJ, Zuidersma M, Groenewold NA De Deyn PP, Luiten PG, Eisel UL, Oude Voshaar RC. Sex-specific associations between Neutrophil Gelatinase-Associated Lipocalin (NGAL) and cognitive domains in late-life depression. Psychoneuroendocrinology. 2014;48:169-77.

72. Naude PJ, Dekker AD, Coppus AM, Vermeiren Y, Eisel UL, van Duijn CM, Van Dam D, De Deyn PP. Serum NGAL is associated with distinct plasma amyloid-beta peptides according to the clinical diagnosis of dementia in down syndrome. J Alzheimers Dis. 2015;45:733-43.

73. Dekens DW, Naude PJ, Engelborghs S, Vermeiren Y, Van Dam D, Oude Voshaar RC, Eisel UL, De Deyn PP. Neutrophil Gelatinase-Associated Lipocalin and its receptors in Alzheimer's disease (AD) brain regions: differential findings in $A D$ with and without depression. J Alzheimers Dis. 2016;55(2):763-76.

74. Vgontzas AN, Zoumakis M, Papanicolaou DA, Bixler EO, Prolo P, Lin HM, Vela-Bueno A, Kales A, Chrousos GP. Chronic insomnia is associated with a shift of interleukin-6 and tumor necrosis factor secretion from nighttime to daytime. Metab Clin Exp. 2002;51:887-92.

75. Huang Y, Potter R, Sigurdson W, Kasten T, Connors R, Morris JC, Benzinger T, Mintun M, Ashwood T, Ferm M, et al. Beta-amyloid dynamics in human plasma. Arch Neurol. 2012;69:1591-7.

76. Bromander S, Anckarsater R, Kristiansson M, Blennow K, Zetterberg H, Anckarsater $\mathrm{H}$, Wass CE. Changes in serum and cerebrospinal fluid cytokines in response to non-neurological surgery: an observational study. J Neuroinflammation. 2012;9:242.

77. Janelidze S, Hertze J, Nagga K, Nilsson K, Nilsson C, Wennstrom M, van Westen D, Blennow K, Zetterberg H, Hansson O. Increased blood-brain barrier permeability is associated with dementia and diabetes but not amyloid pathology or APOE genotype. Neurobiol Aging. 2017;51:104-12.

78. Sawada H, Oeda T, Umemura A, Tomita S, Kohsaka M, Park K, Yamamoto $\mathrm{K}$, Sugiyama $\mathrm{H}$. Baseline $\mathrm{C}$-reactive protein levels and life prognosis in Parkinson disease. PLoS One. 2015;10:e0134118.

79. Goronzy JJ, Weyand CM. Understanding immunosenescence to improve responses to vaccines. Nat Immunol. 2013;14:428-36.

80. Franceschi C, Bonafe M, Valensin S, Olivieri F, De Luca M, Ottaviani E, De Benedictis $G$. Inflamm-aging. An evolutionary perspective on immunosenescence. Ann N Y Acad Sci. 2000:908:244-54.

81. Xia S, Zhang X, Zheng S, Khanabdali R, Kalionis B, Wu J, Wan W, Tai X. An update on inflamm-aging: mechanisms, prevention, and treatment. J Immunol Res. 2016;2016:8426874.

82. El Khoury J. Neurodegeneration and the neuroimmune system. Nat Med. 2010;16:1369-70.

83. Angelova PR, Abramov AY. Alpha-synuclein and beta-amyloid - different targets, same players: calcium, free radicals and mitochondria in the mechanism of neurodegeneration. Biochem Biophys Res Commun. 2016;

84. Forloni G, Artuso V, La Vitola P, Balducci C. Oligomeropathies and pathogenesis of Alzheimer and Parkinson's diseases. Mov Disord. 2016; 31:771-81. 
85. Goedert M. NEURODEGENERATION. Alzheimer's and Parkinson's diseases: the prion concept in relation to assembled Abeta, tau, and alpha-synuclein. Science. 2015;349:1255555.

86. Tanaka S, Ishii A, Ohtaki H, Shioda S, Yoshida T, Numazawa S. Activation of microglia induces symptoms of Parkinson's disease in wild-type, but not in IL-1 knockout mice. J Neuroinflammation. 2013;10:143.

87. Gao HM, Kotzbauer PT, Uryu K, Leight S, Trojanowski JQ, Lee VM. Neuroinflammation and oxidation/nitration of alpha-synuclein linked to dopaminergic neurodegeneration. J Neurosci. 2008;28:7687-98.

88. Sanchez-Guajardo $\mathrm{V}$, Tentillier N, Romero-Ramos M. The relation between alpha-synuclein and microglia in Parkinson's disease: recent developments. Neuroscience. 2015;302:47-58.

89. Brockmann K, Schulte C, Schneiderhan-Marra N, Apel A, Pont-Sunyer C, Vilas D, Ruiz-Martinez J, Langkamp M, Corvol JC, Cormier F, et al. Inflammatory profile discriminates clinical subtypes in LRRK2-associated Parkinson's disease. Eur J Neurol. 2017;24:427-e426.

90. Steimle V, Siegrist CA, Mottet A, Lisowska-Grospierre B, Mach B. Regulation of MHC class II expression by interferon-gamma mediated by the transactivator gene CIITA. Science. 1994;265:106-9.

91. Hamza TH, Zabetian CP, Tenesa A, Laederach A, Montimurro J, Yearout D, Kay DM, Doheny KF, Paschall J, Pugh E, et al. Common genetic variation in the HLA region is associated with late-onset sporadic Parkinson's disease. Nat Genet. 2010;42:781-5.

92. Foltynie T, Brayne C, Barker RA. The heterogeneity of idiopathic Parkinson's disease. J Neurol. 2002;249:138-45.

93. Forlenza OV, Radanovic M, Talib LL, Aprahamian I, Diniz BS, Zetterberg H, Gattaz WF. Cerebrospinal fluid biomarkers in Alzheimer's disease: diagnostic accuracy and prediction of dementia. Alzheimers Dement. 2015;1:455-63.

94. Locascio JJ, Eberly S, Liao Z, Liu G, Hoesing AN, Duong K, TrisiniLipsanopoulos A, Dhima K, Hung AY, Flaherty AW, et al. Association between alpha-synuclein blood transcripts and early, neuroimagingsupported Parkinson's disease. Brain. 2015;138:2659-71.

\section{Submit your next manuscript to BioMed Central and we will help you at every step:}

- We accept pre-submission inquiries

- Our selector tool helps you to find the most relevant journal

- We provide round the clock customer support

- Convenient online submission

- Thorough peer review

- Inclusion in PubMed and all major indexing services

- Maximum visibility for your research

Submit your manuscript at www.biomedcentral.com/submit

) Biomed Central 